\title{
In vitro/vivo drug release and anti-diabetic cardiomyopathy properties of curcumin/PBLG- PEG-PBLG nanoparticles
}

This article was published in the following Dove Press journal: International Journal of Nanomedicine

\author{
Fei Tong \\ Rongkui Chai \\ Haiying Jiang \\ Bo Dong
}

Department of Pathology and Pathophysiology, Provincial Key Discipline of Pharmacology, Jiaxing University Medical College, Jiaxing, Zhejiang, People's Republic of China
Correspondence: Bo Dong Department of Pathology and Pathophysiology, Jiaxing University Medical College, Jiaxing, Zhejiang 3/400I, People's Republic of China Tel +86 I39 57349562

Email dongbo5000@।63.com
Background: The objective of this study was to survey the therapeutic function of curcumin-encapsulated poly(gamma-benzyl l-glutamate)-poly(ethylene glycol)poly(gammabenzyl l-glutamate) (PBLG-PEG-PBLG) (P) on diabetic cardiomyopathy (DCM) via cross regulation effect of calcium-sensing receptor (CaSR) and endogenous cystathionine$\gamma$-lyase (CSE)/hydrogen sulfide $\left(\mathrm{H}_{2} \mathrm{~S}\right)$.

Methods: Diabetic rats were preconditioned with $20 \mathrm{mg} / \mathrm{kg}$ curcumin or curcumin/P complex continuously for 8 weeks. The blood and myocardiums were collected, the level of serum $\mathrm{H}_{2} \mathrm{~S}$ was observed, and the $\left[\mathrm{Ca}^{2+}\right]_{\mathrm{i}}$ content was measured in myocardial cells, and hematoxylin-eosin, CaSR, CSE, and calmodulin (CaM) expression were detected.

Results: Both curcumin and curcumin/P pretreatment alleviated pathological morphological damage of myocardium, increased $\mathrm{H}_{2} \mathrm{~S}$ and $\left[\mathrm{Ca}^{2+}\right]_{\mathrm{i}}$ levels, and upregulated the expression of CaSR, CSE, and $\mathrm{CaM}$ as compared to DCM group, while curcumin/P remarkably augmented this effect.

Conclusion: PBLG-PEG-PBLG could improve water-solubility and bioactivity of curcumin and curcumin/PBLG-PEG-PBLG significantly alleviated diabetic cardiomyopathy.

Keywords: PBLG-PEG-PBLG, curcumin, diabetic cardiomyopathy, CaSR, CSE

\section{Introduction}

Diabetes mellitus (DM) seriously endangers human health, and its incidence is rapidly growing and is becoming a trend in patients of younger age. Worldwide, the population of patients with diabetes is expected to reach 43 billion 900 million by 2030, and about three-quarters of the diabetic patients die from cardiovascular disease. ${ }^{1}$ Diabetic cardiomyopathy (DCM) is caused by diabetes with a heart structure and function disorder, independent of hypertension, coronary atherosclerotic heart disease, valvular heart disease, and other known heart diseases. DCM causes diastolic and/or systolic cardiac function changes, which may eventually lead to myocardial ischemia and heart failure, becoming one of the leading causes of death in diabetics. ${ }^{2}$ The pathogenesis of DCM is very complex and has not been fully elucidated. The current study shows that glucose and lipid metabolism disorders, myocardial fibrosis, oxidative stress, inflammation, apoptosis, and mitochondrial damage play a key role in the pathogenesis of DCM. ${ }^{3-7}$

Following $\mathrm{NO}$ and $\mathrm{CO}$, hydrogen sulfide $\left(\mathrm{H}_{2} \mathrm{~S}\right)$ is a newly discovered endogenous gas signaling molecule that exhibits physiological functions similar to NO, such as vasodilation and apoptosis. ${ }^{8,9}$ Endogenous $\mathrm{H}_{2} \mathrm{~S}$ is produced via cystathionine- $\beta$ synthase (CBS), cystathionine- $\gamma$-lyase (CSE), and cysteine transferase in cells. The distribution of the three key enzymes is not the same in vivo: CBS mainly exists 
in the nervous system (where CSE is absent), and CSE is mainly distributed in the cardiovascular system and the pancreas, such as heart, aorta, pulmonary artery, mesenteric artery, caudal artery, cerebral artery, portal vein, and the beta cells of the pancreas. ${ }^{10}$ The important biological effect of $\mathrm{H}_{2} \mathrm{~S}$ is regulating the apoptosis of cells. ${ }^{11-13}$ Studies have reported that $\mathrm{H}_{2} \mathrm{~S}$ is involved in the regulation of apoptosis in cardiomyocytes and that $\mathrm{H}_{2} \mathrm{~S}$ mainly inhibits apoptosis in the cardiovascular system. ${ }^{11-13}$ The present study shows that endogenous $\mathrm{H}_{2} \mathrm{~S}$ exists widely in the cardiovascular tissues and regulates myocardial function, and inhibits the apoptosis of myocardial cells. ${ }^{14-16}$ In our study, the increase of free calcium in the cells by calmodulin (CaM) and CSE $\left(\mathrm{H}_{2} \mathrm{~S}\right.$ generating enzymes) interaction to impel activation of CSE, and increase $\mathrm{H}_{2} \mathrm{~S}$ production; ${ }^{12}$ the high expression of CSE can inhibit cell apoptosis, and the cells from CSE gene knockout mice show obvious apoptosis. ${ }^{13}$

The calcium-sensing receptor (CaSR) is a member of $\mathrm{G}$ protein-coupled receptor family $\mathrm{C}$ group. CaSR is mainly distributed in the parathyroid gland, heart, kidney, gastrointestinal tract, bone tissue, and other cells such as placenta, lens, breast, and pancreatic beta cells. CaSR not only modulates calcium homeostasis but also regulates cell proliferation, apoptosis, differentiation, and hormone secretion. ${ }^{17}$ Recent studies show that CaSR regulates DCM. ${ }^{18}$ On the other side, some studies show that abnormal regulation of $\mathrm{Ca}^{2+}$ in cells is involved in the development of DCM. ${ }^{18} \mathrm{~A}$ lot of studies also confirm that CaSR promotes the release of $\mathrm{Ca}^{2+}$ from the endoplasmic reticulum and increases intracellular calcium in cardiomyocytes. ${ }^{19,20}$ In addition, the increase of intracellular calcium can enhance the activity of $\mathrm{CaM}$ and regulate a variety of physiological functions, and in turn $\mathrm{Ca}^{2+} / \mathrm{CaM}$ can regulate the activity of CSE and the formation of $\mathrm{H}_{2} \mathrm{~S}$, and ultimately affect apoptosis in the cardiovascular systems. ${ }^{21,22}$

Curcumin, a well-known dietary pigment, derives from Curcuma longa, and modern pharmacological studies show that curcumin has a wide range of pharmacological effects, such as antioxidant, antitumor, anti-inflammatory, and hypolipidemic effects. ${ }^{23-26}$ Many studies have shown that curcumin has therapeutic effects on diabetes, diabetic nephropathy, diabetic eye disease, insulin resistance and metabolism-related diseases, and diabetes-induced endothelial dysfunction. ${ }^{27-31}$ Recent studies have shown that curcumin alleviates DCM. ${ }^{2,32,33}$ However, curcumin has very low water solubility and low bioavailability which limits its clinical application. ${ }^{34}$ The process of curcumin on intestinal absorption induces biotransformation and curcumin is rarely absorbed into the bloodstream by an original drug. ${ }^{35,36}$ In order to improve the solubility of curcumin or dispersion in aqueous solution and

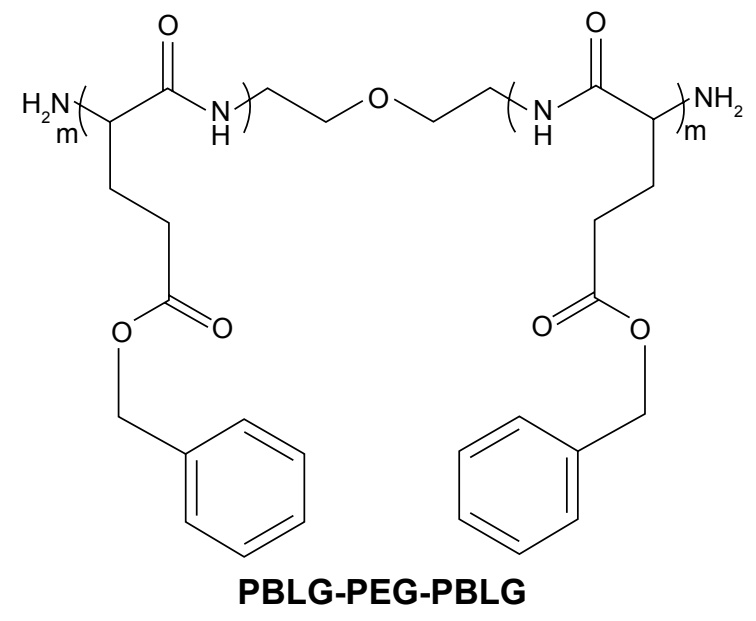

Figure I The structure of PBLG-PEG-PBLG (P). Abbreviation: P, poly(gamma-benzyl L-glutamate)-poly(ethylene glycol)-poly (gamma-benzyl L-glutamate).

increase its biological activity, we synthetized poly(gammabenzyl L-glutamate)-poly(ethylene glycol)-poly(gammabenzyl L-glutamate) (PBLG-PEG-PBLG) (Figures 1 and S1) as potential curcumin carriers. The block multipolymer was synthesized via the ring-opening polymerization of BLG-Ncarboxyanhydride (NCA) with $\mathrm{H}_{2} \mathrm{~N}-\mathrm{PEG}-\mathrm{NH}_{2}$ as the macroinitiator. The PBLG-PEG-PBLG and curcumin integrated into a compound via hydrophobic functions (Scheme 1). In this study, the loading of curcumin into PBLG-PEG-PBLG, the release of curcumin from PBLG-PEG-PBLG, as well as the anti-DCM effect of curcumin/PBLG-PEG-PBLG were measured. The loaded curcumin showed stable release, thus enabling further research on the protective action of curcumin. Curcumin loading and in vitro release were confirmed by dialysis and ${ }^{1} \mathrm{H}$ NMR. In vivo studies indicated that curcumin/ PBLG-PEG-PBLG significantly reduced DCM via cross regulation effect of $\mathrm{CaSR}$ and $\mathrm{CSE} / \mathrm{H}_{2} \mathrm{~S}$.

\section{Materials and methods Materials}

BLG was supplied from Aladdin (Shanghai, China); $\mathrm{H}_{2} \mathrm{~N}-\mathrm{PEG}-$ $\mathrm{NH}_{2}$ (molecular weight=5,000 Da) was supplied from Aladdin; curcumin was bought from Shaanxi Sciphar Biotechnology Co., Ltd. (Xian, China); H9C2 cells were purchased from Shanghai Meixuan Biological Science and Technology Co. Ltd. (Shanghai, China); streptozotocin (STZ) and other reagents were bought from Sigma-Aldrich Co. (St Louis, MO, USA).

\section{Methods}

\section{Synthesis of PBLG-PEG-PBLG (P)}

$\mathrm{P}$ was synthesized according to the procedures described previously. ${ }^{37,38} \mathrm{P}$ was obtained by ring-opening polymerization 


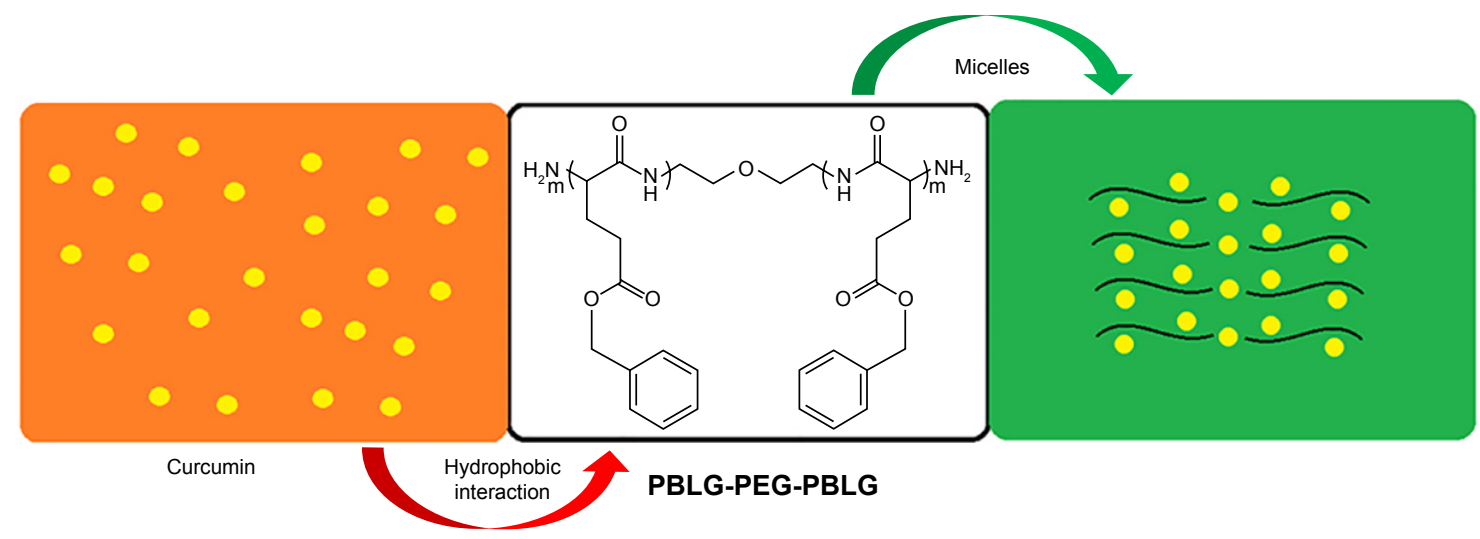

Scheme I Encapsulation of curcumin by PBLG-PEG-PBLG (P).

Abbreviation: P, poly(gamma-benzyl L-glutamate)-poly(ethylene glycol)-poly(gamma-benzyl L-glutamate).

of BLG-NCA with $\mathrm{H}_{2} \mathrm{~N}-\mathrm{PEG}-\mathrm{NH}_{2}$ as the macroinitiator. The right proportion of $\mathrm{H}_{2} \mathrm{~N}-\mathrm{PEG}-\mathrm{NH}_{2}$ in N, N-dimethylformamide (DMF) was mixed with BLG-NCA/DMF fluid via vacuumization and $\mathrm{N}_{2}$ protection. The corresponding compound was stirred at $30^{\circ} \mathrm{C}$ for $72 \mathrm{~h}$ and then dialyzed for $72 \mathrm{~h}$. The $\mathrm{P}$ compound was obtained by freeze drying; the degree of polymerization of PBLG was 50, and the final product was measured via ${ }^{1} \mathrm{H}$-nuclear magnetic resonance ( ${ }^{1} \mathrm{H}$ NMR).

\section{Cytotoxicity measurement of $\mathrm{P}$ and curcumin/P}

For a detailed measurement of cytotoxicity by the cell culture and 3-(4,5-dimethylthiazol-2-yl)-2,5-diphenyltetrazolium bromide (MTT) colorimetric assay (H9C2 cells were selected) of $\mathrm{P}$ and curcumin/P, please refer to our previous studies. ${ }^{39-43}$

\section{Loading of curcumin by $P$}

To observe the encapsulation of curcumin by $\mathrm{P}$, a right amount of curcumin $(5 \mathrm{mg} / \mathrm{mL})$ in phosphate buffered saline (PBS) solution $(\mathrm{pH}=7.2,0.01 \mathrm{mmol} / \mathrm{L})$ was mixed with $\mathrm{P}$ solubilized in PBS and then the obtained solution was dialyzed. The P-encapsulated curcumin was measured through high-pressure liquid chromatography (HPLC), transmission electron microscopy (TEM), and particle size analyzer.

\section{Curcumin release in vitro}

Release of curcumin from $\mathrm{P}$ was observed via a dialysis method at $37^{\circ} \mathrm{C}$, with $5 \mathrm{~mL}$ of curcumin-encapsulated $\mathrm{P}$ against a PB buffer. The curcumin/P complex solutions were prepared as described in the section "Loading of curcumin by P". At fixed time intervals, the amount of curcumin released was observed via HPLC.

\section{Blood curcumin level observation}

Sprague Dawley (SD) male rats (170-250 g) were administrated a dose of $20 \mathrm{mg} / \mathrm{kg}$ curcumin or curcumin $/ \mathrm{P}$ by abdominal subcutaneous injection. About $0.2 \mathrm{~mL}$ of the blood was extracted at fixed time intervals and was subjected to centrifugation $\left(12,000 \times \mathrm{g}\right.$ for $20 \mathrm{~min}$ at $\left.4^{\circ} \mathrm{C}\right)$. The levels of curcumin and curcumin/P in the rat blood were determined by HPLC.

\section{Diabetic animal model}

SD male rats (170-250 g) were obtained from Jiaxing University, Medical College, Jiaxing, China. The procedures and care of SD male rats were authorized through the Institutional Ethics Committee of Jiaxing University, Medical College, Jiaxing, China. The expedition conformed to the guide for the care and use of laboratory animals published through US National Institutes of Health (NIH Publication updated in 2011). SD rats were administrated a high-fat diet (fat content $40 \%$ ) for 10 weeks and then STZ was injected only once at a dose of $35 \mathrm{mg} / \mathrm{kg}$ into the abdominal cavity. After 3 days, diabetes was observed by measuring blood glucose level using glucose oxidase-peroxidase (GOD-POD) ways. ${ }^{44}$ Animals which had blood glucose level $>16.7 \mathrm{mmol} / \mathrm{L}$ were used for further studies.

\section{Histopathological assessment, blood glucose,} cholesterol (Chol), triglyceride (TG), and insulin levels in DM-4w/8w group

Ten SD rats and 20 diabetic rats were assigned to three groups ( $\mathrm{n}=10$, each group): 1) Sham group, 2) DM-4w group, and 3) DM-8w group. At a fixed time interval, histopathological changes, and blood glucose, Chol, TG, and insulin levels were measured via previous methods. ${ }^{18,44,45}$ In brief, the myocardium was fixed in $4 \%$ paraformaldehyde, paraffinembedded, sliced into $4 \mu \mathrm{m}$ sections, and stained with hematoxylin-eosin (HE) staining. The pathological changes at the cellular level were observed under the microscope (Leica 
Microsystems, Wetzlar, Germany) and graded according to the degree of injury based on the percentage of involvement of the myocardium. The extent of injury pertaining to the 10 areas corresponding to the myocardium was graded using the following parameters: hemorrhage, myocardial edema (cytoplasmic vacuole formation), cardiomyocyte apoptosis, and myocardial necrosis based on a 5-point evaluation system $(1=$ histopathological changes $<10 \% ; 2=10 \%-25 \%$; $3=25 \%-50 \% ; 4=50 \%-75 \%$; and 5=75\%-100\%). The mean score for each parameter was calculated and subjected to statistical analysis.

\section{CaSR and CSE expression in DM-4w/8w group}

CaSR and CSE expression were measured via immunohistochemical methods in Sham, DM-4w, and DM-8w groups following the methods described previously. ${ }^{46,47}$

\section{CaSR and CSE expression in DM-8w+CaRS and DM- $8 w+C a R S+P A G$}

Ten SD rats and 10 diabetic rats were assigned to two groups ( $n=10$, each group): Sham group and DM8w+CaRS group. Diabetic rats were administered calcium-sensing receptor stimulator (CaRS) (R-568; $250 \mu \mathrm{g} / \mathrm{d})$ through intraperitoneal injection. CaSR and CSE expression were measured via immunohistochemical methods following the methods described in previous studies. ${ }^{46,47}$ Ten SD rats and 10 diabetic rats were assigned to two groups ( $n=10$, each group): Sham group and DM-8w+CaRS+PAG group. Diabetic rats were administered CaRS (R-568; $250 \mu \mathrm{g} / \mathrm{d})$ and DL-propargylglycine (PAG) $(50 \mathrm{mg} / \mathrm{kg} / \mathrm{d})$ through intraperitoneal injections, respectively. CSE expression was measured via immunohistochemical methods described previously. ${ }^{47}$ All the dosages were selected according to those mentioned in the previous works. ${ }^{48,49}$

\section{Histopathologic assessment, CaSR, CSE, and CaM expression, $\mathrm{H}_{2} \mathrm{~S}$ and $\left[\mathrm{Ca}^{2+}\right]_{i}$ levels (effect of $\mathrm{CaRS}$ and $\mathrm{CaRI}$ )}

Ten SD rats and 70 diabetic rats were assigned to eight groups ( $n=10$, each group): 1) Sham group; 2) DM-8w group; 3) Curcumin group: diabetic rats were administered curcumin $(20 \mathrm{mg} / \mathrm{kg} / \mathrm{d})$ through hypodermic injection for 8 weeks; 4) Curcumin/PBLG-PEG-PBLG (Curcumin/P) group: diabetic rats were administered curcumin/P (20 mg/kg/3 d) through hypodermic injection for 8 weeks; 5) Curcumin+CaRS group: diabetic rats were administered curcumin $(20 \mathrm{mg} / \mathrm{kg} / \mathrm{d})$ through hypodermic injection and CaRS (R-568; $250 \mu \mathrm{g} / \mathrm{d}$ ) through intraperitoneal injection for 8 weeks; 6) Curcumin/
$\mathrm{P}+\mathrm{CaRS}$ group: diabetic rats were administered curcumin/P $(20 \mathrm{mg} / \mathrm{kg} / 3 \mathrm{~d})$ through hypodermic injection and CaRS (R-568; $250 \mu \mathrm{g} / \mathrm{d})$ through intraperitoneal injection for 8 weeks; 7) Curcumin+CaRI group: diabetic rats were administered curcumin $(20 \mathrm{mg} / \mathrm{kg} / \mathrm{d})$ through hypodermic injection and CaRI (NPS2390; $1.5 \mathrm{mg} / \mathrm{kg} / \mathrm{d}$ ) through intraperitoneal injection for 8 weeks; and 8) Curcumin/ $\mathrm{P}+\mathrm{CaRI}$ group: diabetic rats were administered curcumin/P (20 mg/kg/3 d) through hypodermic injection and CaRI (NPS2390; $1.5 \mathrm{mg} / \mathrm{kg} / \mathrm{d}$ ) through intraperitoneal injection for 8 weeks. At a fixed time interval, histopathologic changes (identical to the abovementioned method); CaSR, $\mathrm{CSE}$, and $\mathrm{CaM}$ expression (immunohistochemical methods); and $\mathrm{H}_{2} \mathrm{~S}$ and $\left[\mathrm{Ca}^{2+}\right]_{\mathrm{i}}$ levels were measured via previous methods. ${ }^{45-47,50,51}$ All dosages were in accordance with previous studies. ${ }^{48,52,53}$

\section{Histopathologic assessment, $\mathrm{H}_{2} \mathrm{~S}$ level, and CSE expression (effect of CaRS and PAG)}

Ten SD rats and 70 diabetic rats were assigned to eight groups ( $\mathrm{n}=10$, each group): 1) Sham group; 2) DM-8w group; 3) Curcumin group: diabetic rats were administered by curcumin $(20 \mathrm{mg} / \mathrm{kg} / \mathrm{d})$ through hypodermic injection for 8 weeks; 4) Curcumin/PBLG-PEG-PBLG (Curcumin/P) group: diabetic rats were administered by curcumin/P (20 mg/kg/3 d) through hypodermic injection for 8 weeks; 5) Curcumin+PAG group: diabetic rats were administered curcumin $(20 \mathrm{mg} / \mathrm{kg} / \mathrm{d})$ through hypodermic injection and PAG $(50 \mathrm{mg} / \mathrm{kg} / \mathrm{d})$ through intraperitoneal injection for 8 weeks; 6) Curcumin/P+PAG group: diabetic rats were administered curcumin $/ \mathrm{P}(20 \mathrm{mg} / \mathrm{kg} / 3 \mathrm{~d})$ through hypodermic injection and CaRS $(50 \mathrm{mg} / \mathrm{kg} / \mathrm{d})$ through intraperitoneal injection for 8 weeks; 7) Curcumin+CaRS+PAG group: diabetic rats were administered curcumin $(20 \mathrm{mg} / \mathrm{kg} / \mathrm{d})$ through hypodermic injection, and CaRS (R-568; $250 \mu \mathrm{g} / \mathrm{d}$ ) and PAG $(50 \mathrm{mg} / \mathrm{kg} / \mathrm{d})$ through intraperitoneal injection for 8 weeks; 8) Curcumin/P+CaRS+PAG group: diabetic rats were administered curcumin $/ \mathrm{P}(20 \mathrm{mg} / \mathrm{kg} / 3 \mathrm{~d})$ through hypodermic injection and CaRS (R-568; $250 \mu \mathrm{g} / \mathrm{d})$ and PAG $(50 \mathrm{mg} / \mathrm{kg} / \mathrm{d})$ through intraperitoneal injection for 8 weeks. At a fixed time interval, histopathologic changes (identical to the abovementioned method), $\mathrm{H}_{2} \mathrm{~S}$ level, and CSE expression (immunohistochemical methods) were measured via previous methods. ${ }^{45,47,50}$ All dosages were in accordance with previous studies. ${ }^{48,49,53}$

\section{Apoptosis assessment}

Apoptosis assessment of cardiac cells in Sham, DM-8w, Curcumin, Curcumin/P, Curcumin+CaRS, Curcumin/P+CaRS, 
Curcumin+CaRI, and Curcumin/P+CaRI groups (the grouping was the same as that mentioned earlier) were observed via previous literatures; ${ }^{54}$ apoptosis assessment of cardiac cell in Sham, DM-8w, Curcumin, Curcumin/P, Curcumin+PAG, Curcumin/P+PAG, Curcumin+CaRS+PAG, and Curcumin/ $\mathrm{P}+\mathrm{CaRS}+\mathrm{PAG}$ groups (the grouping was the same as that mentioned earlier) were observed via previous literatures. ${ }^{54}$

\section{Statistical analysis}

Data were expressed as mean \pm standard deviation. All analyses were actualized through SPSS 17.0 software (SPSS, Inc., Chicago, IL, USA). $p<0.01$ was considered to show a statistically significant difference.

\section{Results and discussion \\ Synthesis and characterization of PBLG-PEG-PBLG (P)}

$\mathrm{P}$ was composed of one PEG and two PBLG molecules (Figures 1 and S1). In the present study, the molecular weight of PEG was 5,000 Da, and the degree of polymerization of the PBLG was 50. The procedure of synthesis is described in Figure $\mathrm{S} 1$. The ${ }^{1} \mathrm{H}$ NMR spectra of PBLG-PEG-PBLG is depicted in Figure S2A and Table S1, and the characteristic proton peaks of both PEG and PBLG were observed, corroborating the fact that the synthesis proceeded in a controlled manner and was successful.

\section{Cellular viability measurement}

The cell toxicity of $\mathrm{P}$ and curcumin/P on H9C2 cells were assessed in 24-hour cultures and the results are depicted in Figure S3. The P and curcumin/P micelles showed low cell toxicity even at a concentration as high as $250 \mu \mathrm{g} / \mathrm{mL}$.

\section{Loading capacity of curcumin into $\mathrm{P}$}

Curcumin could be efficiently loaded into $\mathrm{P}$ at $\mathrm{pH} 7.4$ through the hydrophobic interactions. Curcumin was added to P (mass ratios, 1:5) and dialyzed against PBS solution. The dialysis of free curcumin as a control was also conducted at $\mathrm{pH} 7.4$ in a PBS solution. To decide the loading concentration of curcumin into $P$, the quantity of curcumin in the dialysate was determined by HPLC and then deducted from the total quantity of added curcumin. The loading capacity of curcumin was $32.3 \%$ by calculating, expressed as the mass ratios of loaded curcumin to the polymeric compounds host (Table S1).

\section{Characterization estimation of PBLG-PEG-PBLG and curcumin/P}

The $\mathrm{P}$ and curcumin/P were observed through TEM and particle size analyzer and the images are depicted in
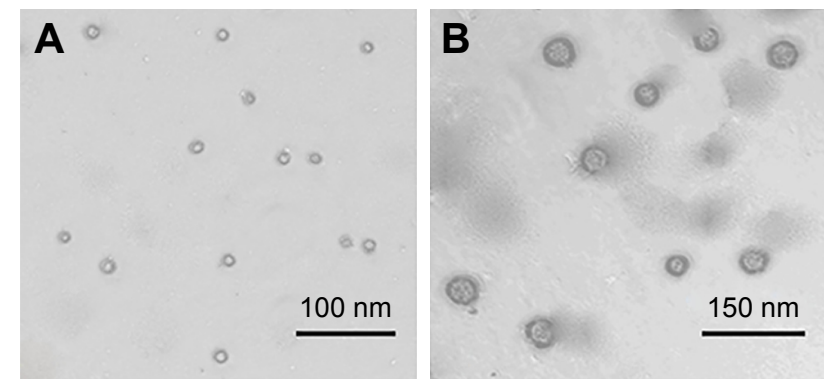

Figure 2 The TEM images of $P$ and curcumin/P.

Notes: (A) TEM of PBLG-PEG-PBLG; (B) TEM of curcumin/PBLG-PEG-PBLG.

Abbreviations: TEM, transmission electron microscopy; $P$, poly(gamma-benzyl L-glutamate)-poly(ethylene glycol)-poly(gamma-benzyl L-glutamate).

Figures 2 and S2B. The particle sizes of $\mathrm{P}$ and curcumin/P were $\sim 12$ and $\sim 30 \mathrm{~nm}$, respectively; the $\mathrm{P}$ and curcumin/P showed an orbicular structure and the diameters were $\sim 47 \mathrm{~nm}$ and $\sim 85 \mathrm{~nm}$, respectively (Table $\mathrm{S} 1$ ).

\section{In vitro releases of curcumin from $P$}

The release of curcumin from $\mathrm{P}$ was measured via a dialysis method at $37^{\circ} \mathrm{C}$, using $5 \mathrm{~mL}$ of curcumin-encapsulated $\mathrm{P}$. The cumulative release ratio of curcumin from curcumin/P is shown in Figure 3. After $0.25 \mathrm{~h}, \sim 9.9 \%$ of the curcumin was released from curcumin/P, indicative of an initial burst release of curcumin. Approximately $94.1 \%$ of the curcumin was released after 3 days.

\section{Plasma curcumin level}

Pharmacodynamic study showed that, in rats treated with curcumin solution, initially the blood curcumin level increased rapidly, reaching the peak within $0.25 \mathrm{~h}(28,300 \mathrm{ng} / \mathrm{mL})$, followed by a significant decline after $4 \mathrm{~h}(0 \mathrm{ng} / \mathrm{mL}$; Figure 4$)$.

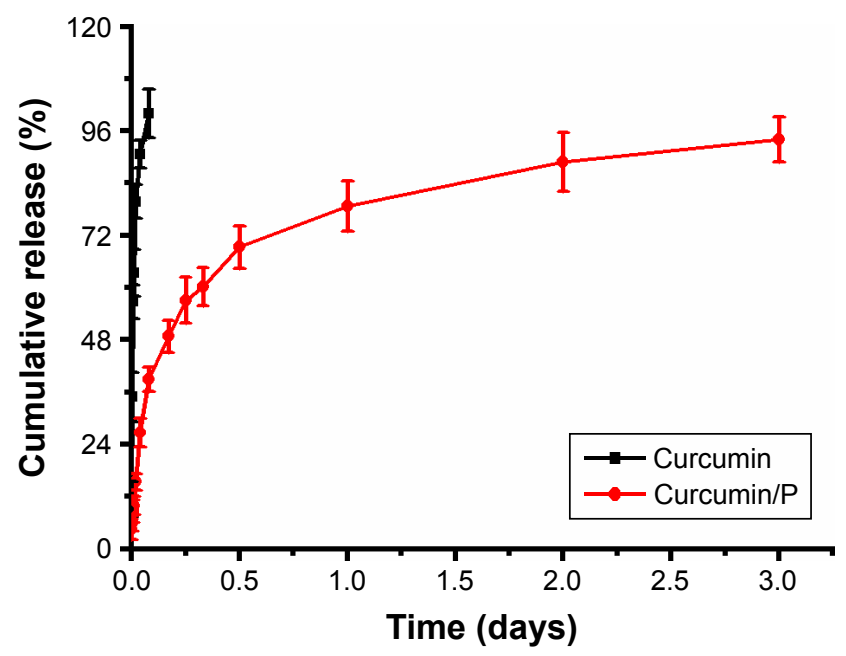

Figure 3 The cumulative releasing profile of free curcumin and curcumin from curcumin/P complexes and results are expressed as mean \pm standard deviation. Abbreviation: P, poly(gamma-benzyl L-glutamate)-poly(ethylene glycol)-poly (gamma-benzyl L-glutamate). 


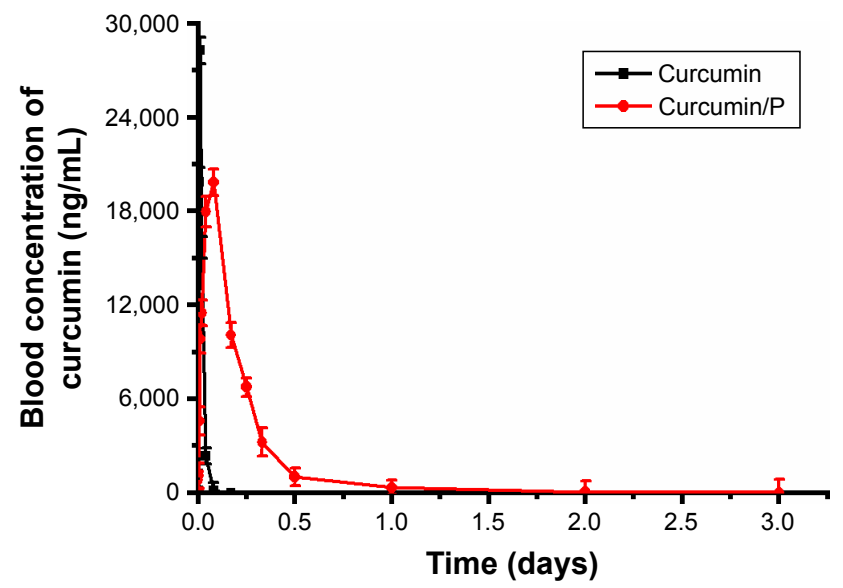

Figure 4 Blood curcumin concentrations of curcumin and curcumin from curcumin/P complexes in rats and results are expressed as mean \pm standard deviation. Abbreviation: P, poly(gamma-benzyl L-glutamate)-poly(ethylene glycol)-poly (gamma-benzyl L-glutamate).
In contrast, the level of the curcumin/P complex gradually peaks within $2 \mathrm{~h}(19,860 \mathrm{ng} / \mathrm{mL})$ and remains at a comparatively low level by 3 days $(8 \mathrm{ng} / \mathrm{mL}$ on day 3 ; Figure 4$)$.

Previous studies had affirmed that curcumin exhibited low water solubility, low bioavailability, and short halftime. ${ }^{34-36}$ In this study, the blood curcumin level revealed that $\mathrm{P}$ could improve the pharmacological action and half-time of curcumin.

\section{Histopathologic assessment in DM-4w/8w group}

Light microscopy image of myocardium sections are shown in Figure 5A. The disordered arrangement of myocardial cells, inflammatory reactions, T-cell and activated macrophage infiltration, edema, myofibril disarray, cell death, fibrosis,

A
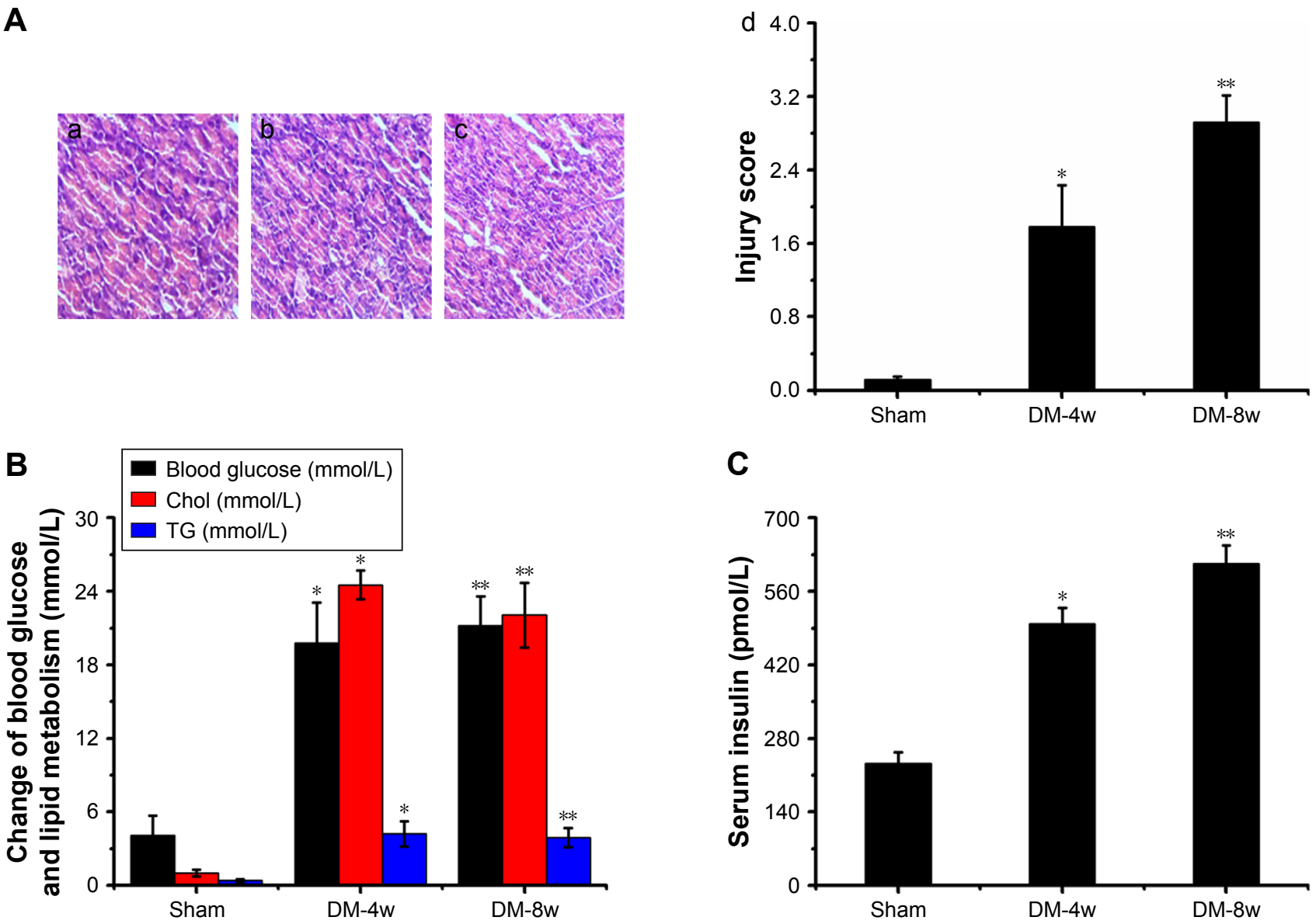

C

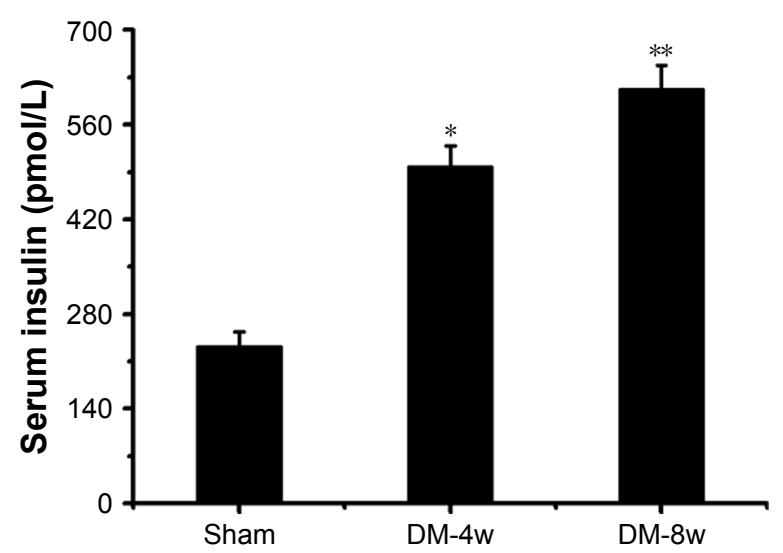

Figure 5 (A) Histopathologic assessment of myocardial damage; (B) blood glucose, Chol, and TG levels; (C) serum insulin level.

Notes: $(\mathbf{A})$ Light microscope images $(\times 100)$ in Sham group (a), DM-4w group (b), and DM-8w group (c). The quantitative analysis of histopathologic assessment is shown in " $\mathrm{d}$ ". Results are expressed as mean \pm SD. A significant increase from Sham group is denoted by * $<<0.01$, and a significant increase from DW-4w group is denoted by $*^{* *}<0.0$ I. (B) The blood of Sham, DM-4w, and DM-8w groups were collected, and the levels of blood glucose, Chol, and TG were measured. Results are expressed as mean $\pm S D$. A significant increase from Sham group is denoted by ${ }^{*} p<0.01$, and a significant increase from DW-4w group is denoted by $* * p<0.01$. (C) The blood of Sham, $D M-4 w$, and DM-8w groups were collected and the levels of serum insulin were measured. Results are expressed as mean \pm SD. A significant increase from Sham group is denoted by $* p<0.01$, and a significant increase from DW- 4 w groups is denoted by $* * p<0.01$.

Abbreviations: DM, diabetes mellitus; Chol, cholesterol; TG, triglyceride; SD, standard deviation. 
myocardial cell membrane rupture and fuzzy edges, vacuolar degeneration, and derangement were observed in histological specimen from the DM-4w group (Figure 5A-a) but were absent in the Sham group (Figure 5A-b). Histological alteration was aggravated in specimens from the DM-8w group (Figure 5A-c) compared to the DM-4w group. The quantitative analysis of histological alteration is shown in Figure 5A-d.

Based on a previous document, ${ }^{55}$ in the current study, diabetes induced the myocardial damage in DM-4W group and aggravated myocardial injury in DM-8w group compared to Sham group. The results showed that DCM model was successfully established.

\section{Blood glucose, Chol,TG, and insulin levels in DM-4w/8w group}

Blood glucose levels were observed in DM-4w and DM-8w (Figure 5B) groups and were higher in the DM-4w group ( $p<0.01$; blood glucose: Sham group $4.1 \pm 1.6 \mathrm{mmol} / \mathrm{L}$, DM-4w group $19.8 \pm 3.3 \mathrm{mmol} / \mathrm{L})$ and significantly higher in the DM-8w group ( $p<0.01$; blood glucose: DM-8w group $21.2 \pm 2.4 \mathrm{mmol} / \mathrm{L}$ ) when compared to the Sham group.

Levels of Chol were observed in DW-4w and DW-8w (Figure 5B) groups and were significantly higher in the DM-4w group $(p<0.01$; Chol: Sham group $1.02 \pm 0.89$ $\mathrm{mmol} / \mathrm{L}, \mathrm{DM}-4 \mathrm{w}$ group $24.53 \pm 3.17 \mathrm{mmol} / \mathrm{L}$ ) and DM-8w group ( $p<0.01$; Chol: DM-8w group 22.06 $\pm 2.65 \mathrm{mmol} / \mathrm{L}$ ) than in the Sham group.

Levels of TG were observed in DM-4w and DM-8w (Figure 5B) groups and were significantly higher in the DM-4w group $(p<0.01$; TG: Sham group $0.41 \pm 0.11 \mathrm{mmol} / \mathrm{L}$, DM-4w group $4.21 \pm 1.02 \mathrm{mmol} / \mathrm{L}$ ) and DM-8w group $(p<0.01$; TG: DM-8w group $3.91 \pm 0.78 \mathrm{mmol} / \mathrm{L})$ than in the Sham group.

Levels of serum insulin were observed in DM-4w and DM-8w groups (Figure 5C) and were higher in the DM-4w group ( $p<0.01$; serum insulin: Sham group 232.38 \pm 21.38 $\mathrm{pmol} / \mathrm{L}, \mathrm{DM}-4 \mathrm{w}$ group $498.76 \pm 29.86 \mathrm{pmol} / \mathrm{L})$ and significantly higher in DM-8w group $(p<0.01$; serum insulin: DM- $8 \mathrm{w}$ group $613.29 \pm 34.11 \mathrm{pmol} / \mathrm{L}$ ) than in the Sham group.

Based on previous literature, ${ }^{18}$ in this study, a highglucose and high-fat diet combined with intraperitoneal injection of small dose of STZ was used to replicate the animal model of type 2 DCM in rats. When compared to the Sham group, blood glucose, TG, and Chol levels increased significantly in model group rats. Serum insulin levels were also significantly increased in the model group rats, indicating the occurrence of insulin resistance. The results showed that this experiment successfully established a rat animal model of type 2 DCM.

\section{CaSR and CSE expression in DM-4w/8w group}

CaSR expression in DM-4w and DM-8w (Figure 6A) groups and was lower in the DM-4w group than in the Sham group, the CaSR expression was significantly lower than in the Sham group; CSE expression in DM-4w and DM-8w (Figure 6B) groups and was lower in the DM-4w group than in the Sham group, the CSE expression was significantly lower than in the Sham group. CaSR expression in the DM-8w+CaRS group (Figure 6C) was significantly higher than in the Sham group. CSE expression in the DM-8w+CaRS (Figure 6D) group was significantly higher than in the Sham group; CSE expression in the DM- $8 w+C a R S+P A G$ group (Figure 6E) was higher than in the Sham group.

The pathogenesis of DCM was very complex. We authenticated that the expression of CaSR and CSE decreased in DM-4w and DM-8w groups, and the expression of CaSR and CSE were significantly lower in DM-8w than that in DM-4w group. The result showed that the expression of myocardial CaSR and CSE in diabetic rats decreased in a time-dependent manner and closely related to the changes of myocardial histopathological damage. Previous literature had proved that the decreased expression of CaSR and CSE in rat mesenteric arteries were one of the important causes for diabetic vascular complications. ${ }^{50}$ Other organs in diabetic or obese rats were the same as the myocardium we observed, and the expression of CaSR and CSE were also reduced. On the other hand, it also showed that CaSR modulated CSE to regulate DCM in this study.

\section{Effect of CaRS and CaRI on} histopathologic assessment, CaSR, CaM, and CSE expression, $\mathrm{H}_{2} \mathrm{~S}$ and $\left[\mathrm{Ca}^{+}\right]_{i}$ levels

Light microscopy images of myocardium sections in Sham, DM-8w, Curcumin, Curcumin/P, Curcumin+CaRS, Curcumin/P+CaRS, Curcumin+CaRI, and Curcumin/P+CaRI groups are shown in Figure 7A. The disordered arrangement of myocardial cells, inflammatory reactions, T-cell and activated macrophage infiltration, edema, myofibril disarray, cell death, fibrosis, myocardial cell membrane rupture and fuzzy edges, vacuolar degeneration, and derangement were observed in the histological specimens from the DM-8w group (Figure 7A-a) but were absent in the Sham group (Figure 7A-b). The histopathologic damage in the Curcumin, 
A

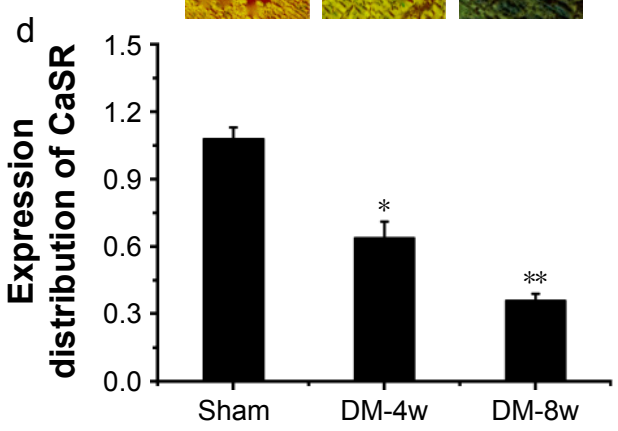

B

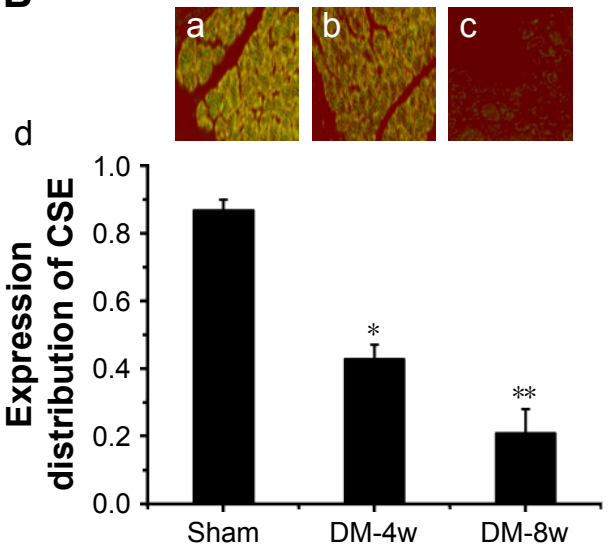

C
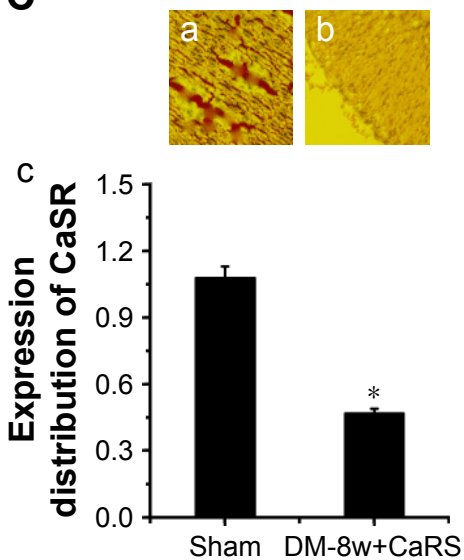

D
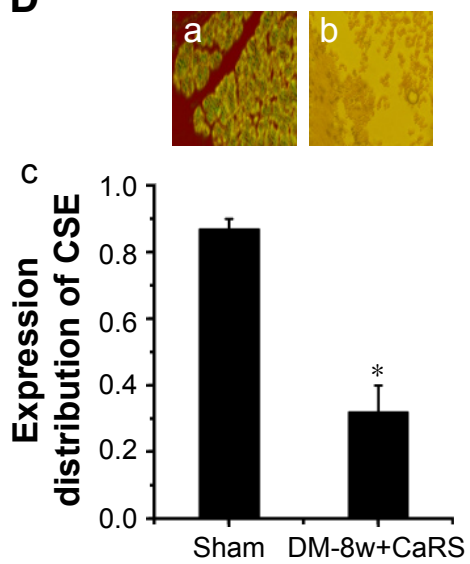

$\mathbf{E}$
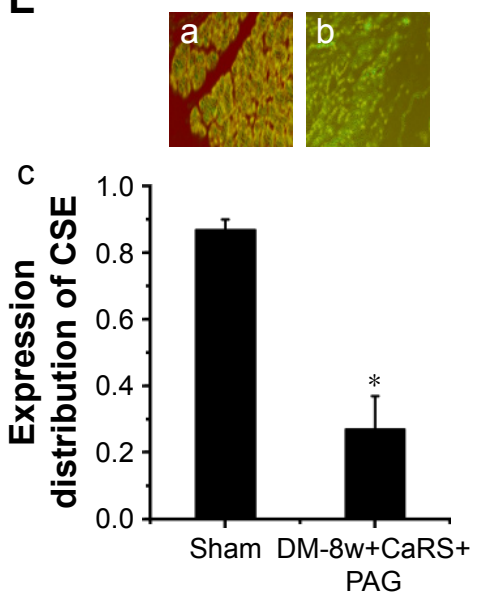

Figure 6 (A) CaSR expression in Sham, DM-4w, and DM-8w groups; (B) CSE expression in Sham, DM-4w, and DM-8w groups; (C) CaSR expression in Sham and DM$8 w+C a R S$ groups; (D) CSE expression in Sham and DM-8w+CaRS groups; (E) CSE expression in Sham and DM-8w+CaRS+PAG groups.

Notes: (A) CaSR expression in Sham group (a), DM-4w group (b), and DM-8w group (c). The quantitative analysis of CaSR expression is shown in "d". Results are expressed as mean \pm SD. (B) CSE expression in Sham group (a), DM-4w group (b), and DM-8w group (c). The quantitative analysis of CSE expression is shown in "d". Results are expressed as mean \pm SD. (C) CaSR expression in Sham group (a), DM-8w+CaRS group (b). The quantitative analysis of CaSR expression is shown in "c". Results are expressed as mean \pm SD. (D) CSE expression in Sham group (a) and DM-8w+CaRS group (b). The quantitative analysis of CSE expression is shown in "c". Results are expressed as mean \pm SD. (E) CSE expression in Sham group (a) and DM-8w+CaRS+PAG group (b). The quantitative analysis of CSE expression is shown in "c". Results are expressed as mean $\pm S D$. Magnification is $\times 100$. A significant decrease from Sham group is denoted by $* p<0.0$ I, and a significant decrease from $D W-4 w$ group is denoted by $* * p<0.01$.

Abbreviations: CaSR, calcium-sensing receptor; DM, diabetes mellitus; CSE, cystathionine- $\gamma$-lyase; CaRS, calcium-sensing receptor stimulator; PAG, DL-propargylglycine.

Curcumin $+\mathrm{CaRS}$, and Curcumin $+\mathrm{CaRI}$ groups was lower than that in the DM- $8 \mathrm{w}$ group (Figure 7A-c, e, g); the histopathologic damage in Curcumin/P, Curcumin/P+CaRS, and Curcumin $/ \mathrm{P}+\mathrm{CaRI}$ groups was significantly lower than in the DM-8w group (Figure 7A-d, f, h). The quantitative analysis of histological assessment is shown in Figure 7A-i.

CaSR expression in Sham, DM-8w, Curcumin, Curcumin/P, Curcumin $+\mathrm{CaRS}$, Curcumin/P+CaRS, Curcumin+CaRI, and Curcumin/P+CaRI groups are shown in Figure $8 \mathrm{~B}$. The CaSR expression was significantly lower in the DM-8w group than that in the Sham group (Figure 7B-a, b); the CaSR expression was higher in the Curcumin, Curcumin+CaRS, and Curcumin+CaRI groups than that in the DM- $8 \mathrm{w}$ group
(Figure 7B-c, e, g), the CaSR expression was significantly higher in the Curcumin/P, Curcumin/P+CaRS, and Curcumin/ $\mathrm{P}+\mathrm{CaRI}$ groups than in the DM- $8 \mathrm{w}$ group (Figure $7 \mathrm{~B}-\mathrm{d}, \mathrm{f}$, h). The quantitative analysis of CaSR expression is shown in Figure 7B-i.

CSE expression in Sham, DM-8w, Curcumin, Curcumin/P, Curcumin $+\mathrm{CaRS}$, Curcumin/P+CaRS, Curcumin+CaRI, and Curcumin $/ \mathrm{P}+\mathrm{CaRI}$ groups are shown in Figure $7 \mathrm{C}$. The CSE expression was significantly lower in DM-8w group than that in Sham group (Figure 7C-a, b). The CSE expression was higher in Curcumin group, Curcumin $+\mathrm{CaRS}$ group, and Curcumin+CaRI group than in DM- $8 \mathrm{w}$ group (Figure 7C-c, e, g). The CSE expression was significantly 
higher in Curcumin/P group, Curcumin/ $\mathrm{P}+\mathrm{CaRS}$ group, and Curcumin $/ \mathrm{P}+\mathrm{CaRI}$ group than that in DM- $8 \mathrm{w}$ group (Figure 7C-d, f, h). The quantitative analysis of CSE expression is shown in Figure 7C-i.

$\mathrm{H}_{2} \mathrm{~S}$ level in Sham, DM-8w, Curcumin, Curcumin/P, Curcumin + CaRS, Curcumin/P+CaRS, Curcumin $+\mathrm{CaRI}$, and Curcumin/P+CaRI groups are shown in Figure $7 \mathrm{D}$. The $\mathrm{H}_{2} \mathrm{~S}$ level was significantly lower in DM-8w group than that in Sham group $\left(p<0.01 ; \mathrm{H}_{2} \mathrm{~S}\right.$ level: Sham group $39.1 \pm 2.79 \mathrm{~mol} / \mathrm{L}, \mathrm{DM}-8 \mathrm{w}$ group $11.3 \pm 1.18 \mathrm{~mol} / \mathrm{L}$ ). The $\mathrm{H}_{2} \mathrm{~S}$ level was higher in Curcumin group, Curcumin+CaRS group, and Curcumin+CaRI group than that in DM- $8 \mathrm{w}$ group $\left(p<0.01 ; \mathrm{H}_{2} \mathrm{~S}\right.$ level: Curcumin group $17.9 \pm 1.94 \mathrm{~mol} / \mathrm{L}$, Curcumin+CaRS group $19.6 \pm 1.66 \mathrm{~mol} / \mathrm{L}$, Curcumin+CaRI group $15.4 \pm 1.47 \mathrm{~mol} / \mathrm{L}$ ). The $\mathrm{H}_{2} \mathrm{~S}$ level was significantly higher in Curcumin/P group, Curcumin/P+CaRS group, and Curcumin $/ \mathrm{P}+\mathrm{CaRI}$ group than that in $\mathrm{DM}-8 \mathrm{w}$ group $\left(p<0.01 ; \mathrm{H}_{2} \mathrm{~S}\right.$ level: Curcumin/P group $24.2 \pm 2.01 \mathrm{~mol} / \mathrm{L}$,
Curcumin/P+CaRS group 26.8 $\pm 1.89 \mathrm{~mol} / \mathrm{L}$, Curcumin/ $\mathrm{P}+\mathrm{CaRI}$ group $22.3 \pm 1.55 \mathrm{~mol} / \mathrm{L}$ ).

$\left[\mathrm{Ca}^{2+}\right]_{\mathrm{i}}$ level in Sham, DM-8w, Curcumin, Curcumin/P, Curcumin $+\mathrm{CaRS}$, Curcumin/P+CaRS, Curcumin $+\mathrm{CaRI}$, and Curcumin/P+CaRI groups are shown in Figure 7E. The $\left[\mathrm{Ca}^{2+}\right]_{\mathrm{i}}$ level was significantly lower in DM-8w group than that in Sham group $\left(p<0.01 ;\left[\mathrm{Ca}^{2+}\right]_{\mathrm{i}}\right.$ level: Sham group 179.3 \pm 4.8 $\mathrm{nmol} / \mathrm{L}, \mathrm{DM}-8 \mathrm{w}$ group $41.8 \pm 1.7 \mathrm{nmol} / \mathrm{L})$. The $\left[\mathrm{Ca}^{2+}\right]_{\mathrm{i}}$ level was higher in Curcumin group, Curcumin+CaRS group, and Curcumin $+\mathrm{CaRI}$ group than that in DM- $8 \mathrm{w}$ group $\left(p<0.01 ;\left[\mathrm{Ca}^{2+}\right]_{\mathrm{i}}\right.$ level: Curcumin group $71.4 \pm 2.1 \mathrm{nmol} / \mathrm{L}$, Curcumin+CaRS group $82.3 \pm 3.2 \mathrm{nmol} / \mathrm{L}$, Curcumin+CaRI group $58.2 \pm 4.3 \mathrm{nmol} / \mathrm{L}$ ). The $\left[\mathrm{Ca}^{2+}\right]_{\mathrm{i}}$ level was significantly higher in Curcumin/P group, Curcumin/ $\mathrm{P}+\mathrm{CaRS}$ group, and Curcumin $/ \mathrm{P}+\mathrm{CaRI}$ group than that in $\mathrm{DM}-8 \mathrm{w}$ group $\left(p<0.01 ;\left[\mathrm{Ca}^{2+}\right]_{\mathrm{i}}\right.$ level: Curcumin/P group $118.9 \pm 1.6 \mathrm{nmol} / \mathrm{L}$, Curcumin/P+CaRS group 131.5 $\pm 2.7 \mathrm{nmol} / \mathrm{L}$, Curcumin/ $\mathrm{P}+\mathrm{CaRI}$ group $91.4 \pm 3.8 \mathrm{nmol} / \mathrm{L}$ ).
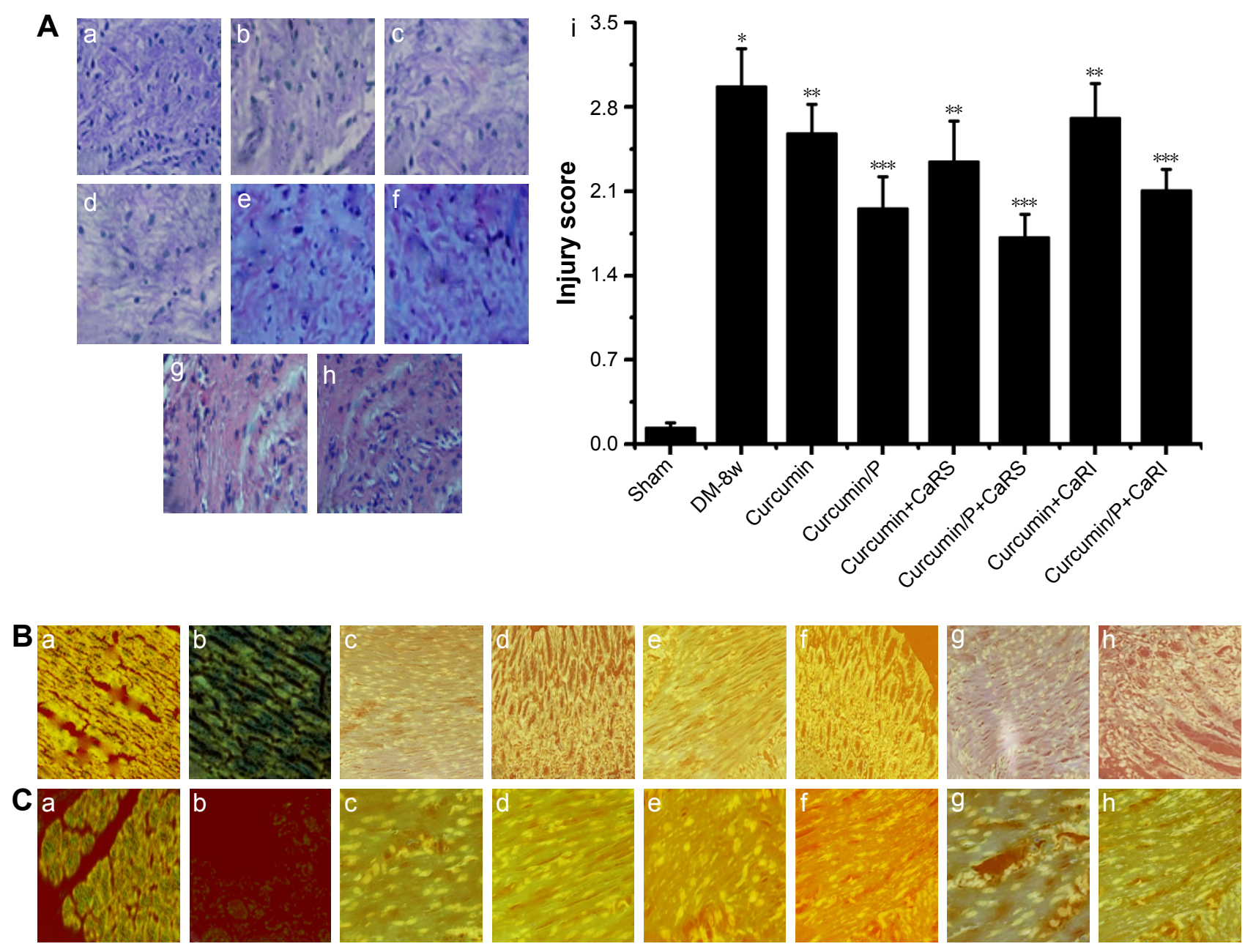

Figure 7 (Continued) 


\section{B-i}
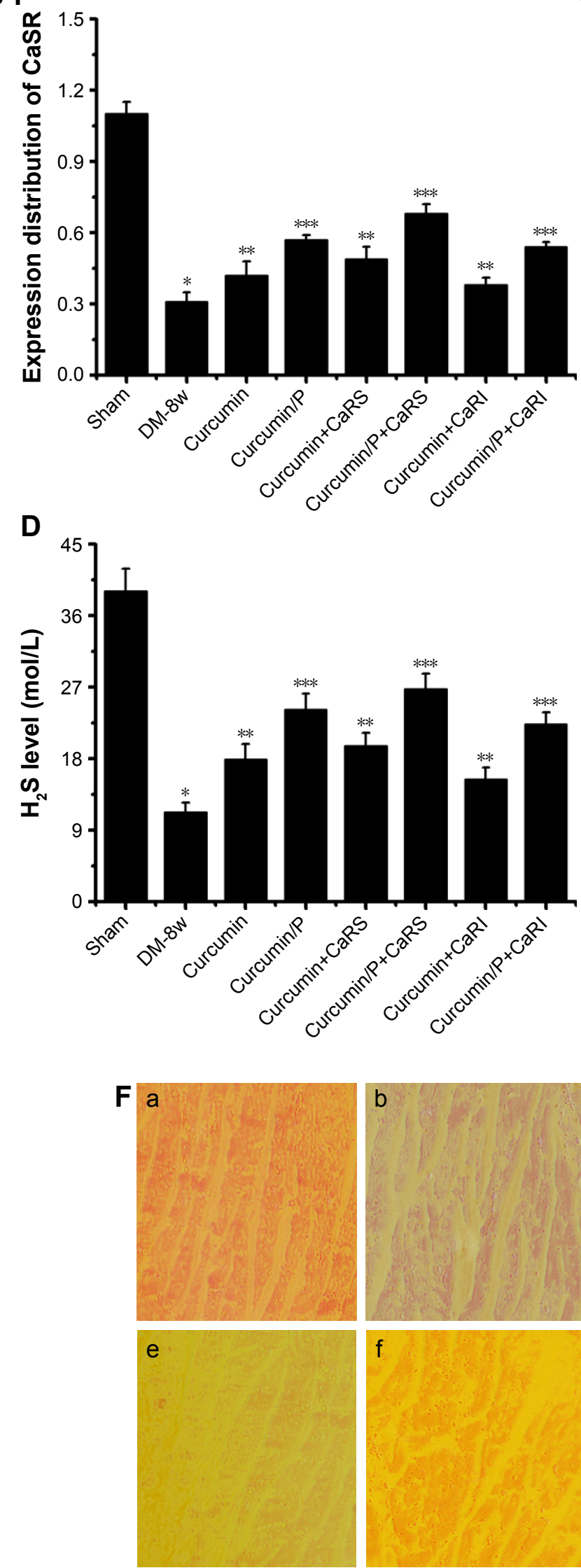

C-i

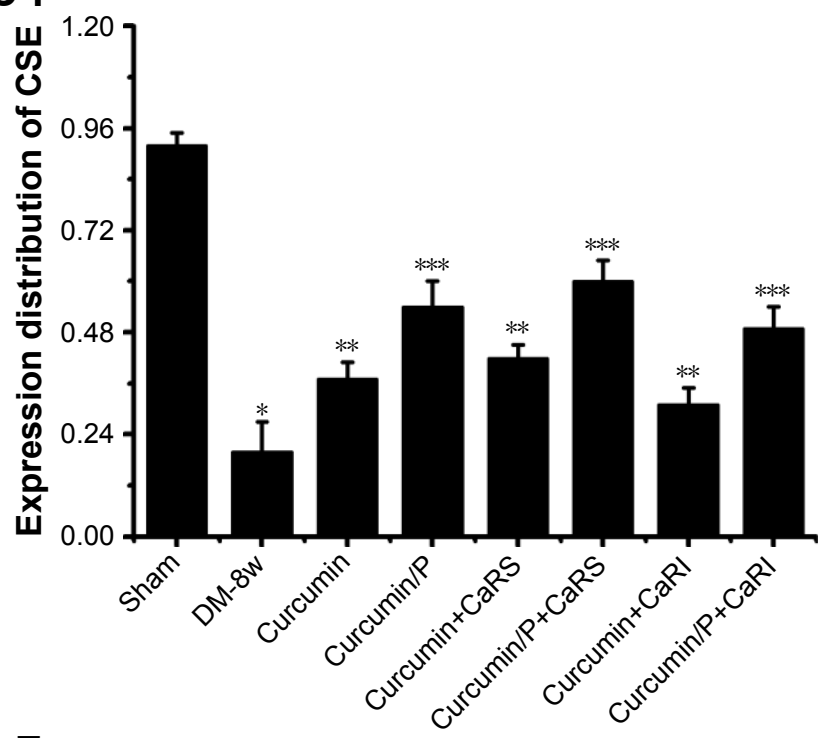

E
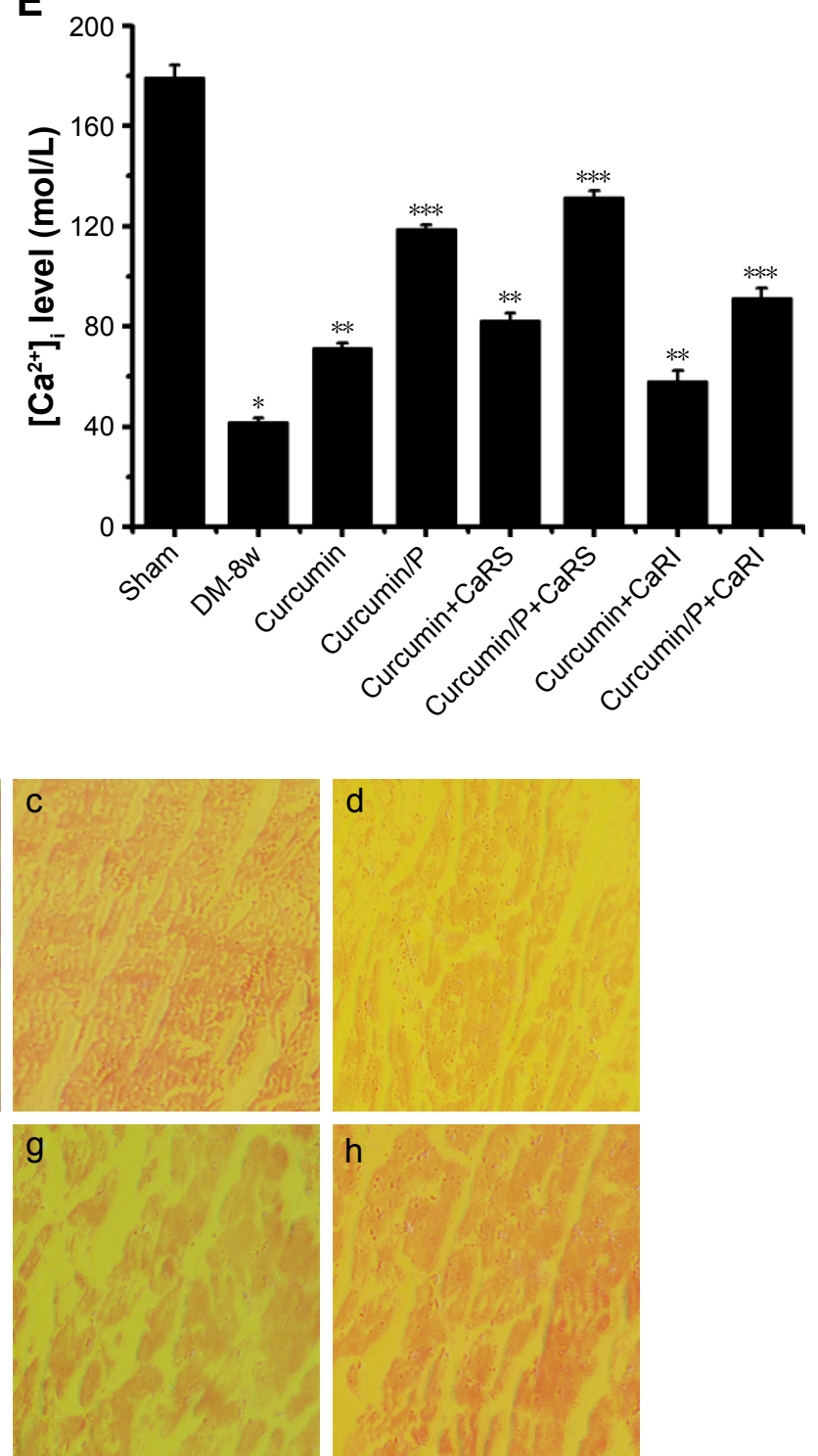

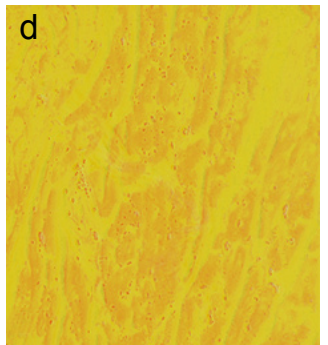

h

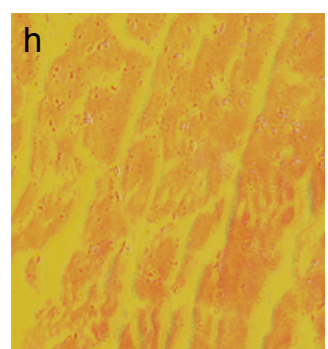




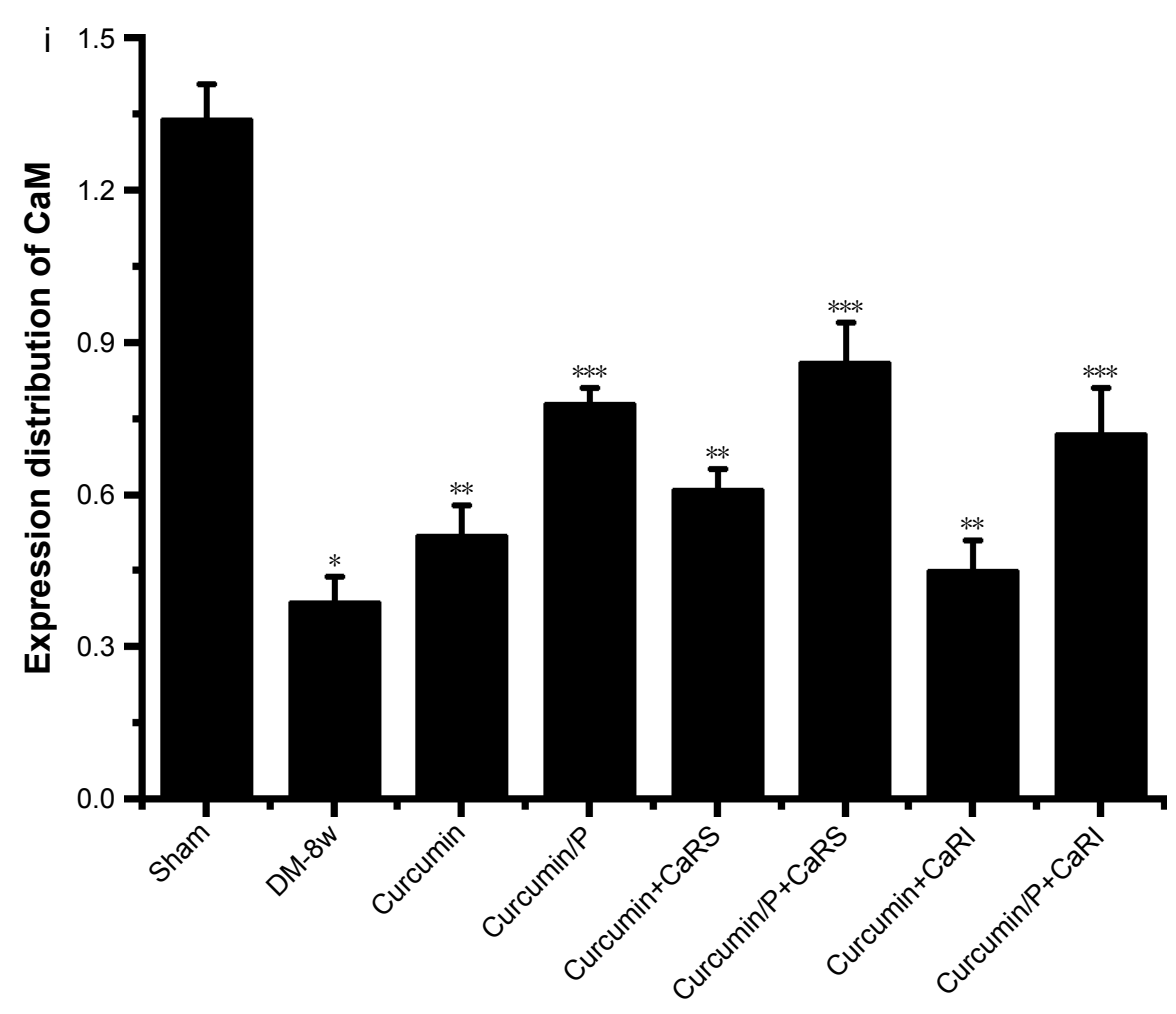

Figure 7 (A) Histopathologic assessment of myocardial damage; (B) CaSR expression in Sham, DM-8w, Curcumin, Curcumin/P, Curcumin+CaRS, Curcumin/P+CaRS, Curcumin+CaRI, and Curcumin/P+CaRI groups; (C) CSE expression in Sham, DM-8w, Curcumin, Curcumin/P, Curcumin+CaRS, Curcumin/P+CaRS, Curcumin+CaRI, and Curcumin/P+CaRI groups; (D) $\mathrm{H}_{2} \mathrm{~S}$ level in Sham, DM-8w, Curcumin, Curcumin/P, Curcumin+CaRS, Curcumin/P+CaRS, Curcumin+CaRI, and Curcumin/P+CaRI groups; (E) $\left[\mathrm{Ca}^{2+}\right]_{i}$ level in Sham, DM-8w, Curcumin, Curcumin/P, Curcumin+CaRS, Curcumin/P+CaRS, Curcumin+CaRI, and Curcumin/P+CaRI groups; (F) CaM expression in Sham, DM-8w, Curcumin, Curcumin/P, Curcumin+CaRS, Curcumin/P+CaRS, Curcumin+CaRI, and Curcumin/P+CaRI groups.

Notes: (A) Light microscope images $(\times 100)$ in Sham group (a), DM-8w group (b), Curcumin group (c), Curcumin/P group (d), Curcumin + CaRS group (e), Curcumin/P+CaRS group (f), Curcumin+CaRI group (g), and Curcumin/P+CaRI group (h). The quantitative analysis of histopathological assessment is shown in "i". The histopathologic damage in DM-8w group is higher than that in Sham group $(p<0.0 \mathrm{I})$, and the histopathologic damage in Curcumin group, Curcumin+CaRS group, and Curcumin + CaRI group is lower than that in DM-8w group $(p<0.01)$; the histopathologic damage in Curcumin/P group, Curcumin/P+CaRS group, and Curcumin/P+CaRI group is significantly lower than that in DM-8w group $(p<0.0 \mathrm{I})$. (B) CaSR expression in Sham group (a), DM-8w group (b), Curcumin group (c), Curcumin/P group (d), Curcumin+CaRS group (e), Curcumin/ $P+C a R S$ group $(f)$, Curcumin+CaRI group $(g)$, and Curcumin/P+CaRI group $(h)$. The quantitative analysis of CaSR expression is shown in "B-i". The CaSR expression in DM-8w group is lower than that in Sham group $(p<0.01)$, and the CaSR expression in Curcumin group, Curcumin+CaRS group, and Curcumin + CaRI group is higher than that in DM-8w group $(p<0.01)$; the CaSR expression in Curcumin/P group, Curcumin/P+CaRS group, and Curcumin/P+CaRI group is significantly higher than that in DM-8w group $(p<0.01)$. (C) CSE expression in Sham group (a), DM-8w group (b), Curcumin group (c), Curcumin/P group (d), Curcumin+CaRS group (e), Curcumin/P+CaRS group ( $)$, Curcumin+CaRI group $(\mathrm{g})$, and Curcumin/P+CaRI group $(\mathrm{h})$. The quantitative analysis of CSE expression is shown in "C-i". The CSE expression in DM-8w group is lower than that in Sham group $(p<0.0 \mathrm{I})$, and the CSE expression in Curcumin group, Curcumin+CaRS group, and Curcumin $+\mathrm{CaRI}$ group is higher than that in DM- $8 \mathrm{w}$ group ( $p<0.0 \mathrm{I})$; the CSE expression in Curcumin/P group, Curcumin/P+CaRS group, and Curcumin/P+CaRI group is significantly higher than that in DM-8w group ( $p<0.0 \mathrm{I}$ ). (D) The blood of Sham, DM-8w, Curcumin, Curcumin/P, Curcumin+CaRS, Curcumin/ $\mathrm{P}+\mathrm{CaRS}$, Curcumin+CaRI, and Curcumin/P+CaRI groups were collected and the levels of $\mathrm{H}_{2} \mathrm{~S}$ were measured. Results are expressed as mean \pm SD. (E) The cardiac cells of Sham, DM- $8 w$, Curcumin, Curcumin/P, Curcumin + CaRS, Curcumin/P $+C a R S, C u r c u m i n+C a R I$, and

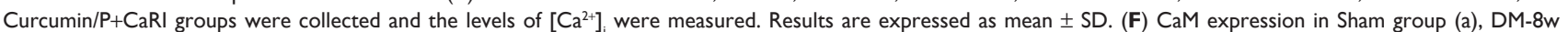
group (b), Curcumin group (c), Curcumin/P group (d), Curcumin+CaRS group (e), Curcumin/P+CaRS group (f), Curcumin+CaRI group (g), and Curcumin/P+CaRI group (h). The quantitative analysis of CaM expression is shown in "i". The CaM expression in DM-8w group is lower than that in Sham group ( $p<0.0 \mathrm{I})$, and the CaM expression in Curcumin group, Curcumin+CaRS group, and Curcumin+CaRI group is higher than that in DM-8w group $(p<0.0 \mathrm{I})$; the CaM expression in Curcumin/P group, Curcumin/ $\mathrm{P}+\mathrm{CaRS}$ group, and Curcumin $/ \mathrm{P}+\mathrm{CaRI}$ group is significantly higher than that in $\mathrm{DM}-8 \mathrm{w}$ group $(p<0.0 \mathrm{I})$. A significant decrease from Sham group is denoted by $* p<0.0 \mathrm{I}$, a significant increase from DM- $8 w$ group is denoted by ${ }^{* *} p<0.0 \mathrm{I}$, and a significant increase from DM-8w group is denoted by $* * * p<0.0 \mathrm{I}$.

Abbreviations: CaSR, calcium-sensing receptor; DM, diabetes mellitus; CSE, cystathionine- $\gamma$-lyase; CaRS, calcium-sensing receptor stimulator; CaRI, calcium-sensing receptor inhibitor; CaM, calmodulin; P, poly(gamma-benzyl L-glutamate)-poly(ethylene glycol)-poly(gamma-benzyl L-glutamate); SD, standard deviation.

CaMexpression in Sham, DM-8w, Curcumin, Curcumin/P, Curcumin $+\mathrm{CaRS}$, Curcumin/P+CaRS, Curcumin $+\mathrm{CaRI}$, and Curcumin $/ \mathrm{P}+\mathrm{CaRI}$ groups are shown in Figure $7 \mathrm{~F}$. The $\mathrm{CaM}$ expression was significantly lower in DM-8w group than that in Sham group (Figure 7F-a, b). The CaM expression was higher in Curcumin group, Curcumin+CaRS group, and Curcumin+CaRI group than in DM-8w group (Figure 7F-c, e, g). The CaM expression was significantly higher in
Curcumin/P group, Curcumin/P+CaRS group, and Curcumin/ $\mathrm{P}+\mathrm{CaRI}$ group than that in DM-8w group (Figure 7F-d, f, h). The quantitative analysis of CaM expression is shown in Figure 7F-i.

$\mathrm{CaSR}$, as a $\mathrm{G}$ protein-coupled receptor, could modulate intracellular $\left[\mathrm{Ca}^{2+}\right]_{\mathrm{i}}$ levels and promote $\left[\mathrm{Ca}^{2+}\right]$ release from the endoplasmic/sarcoplasmic reticulum. ${ }^{19,56}$ Previous study had showed that increased $\left[\mathrm{Ca}^{2+}\right]_{\mathrm{i}}$ levels could promote CSE 
A
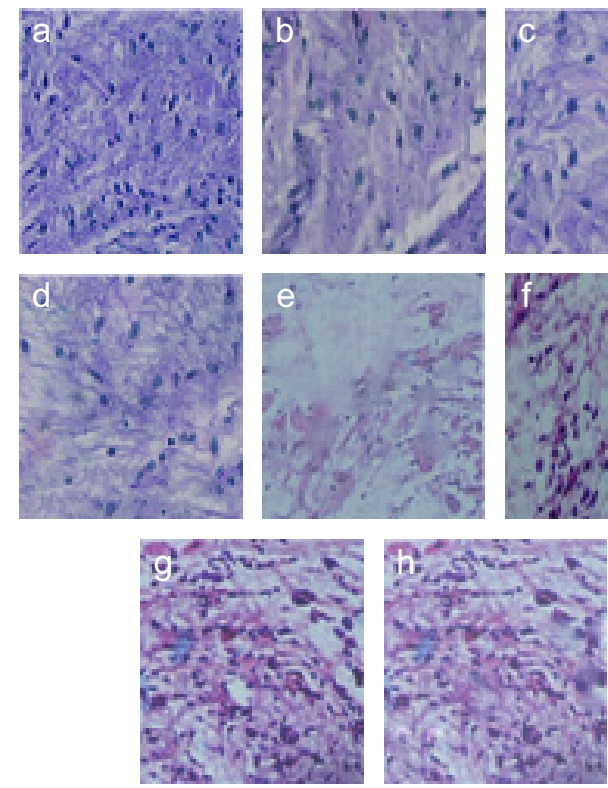

B

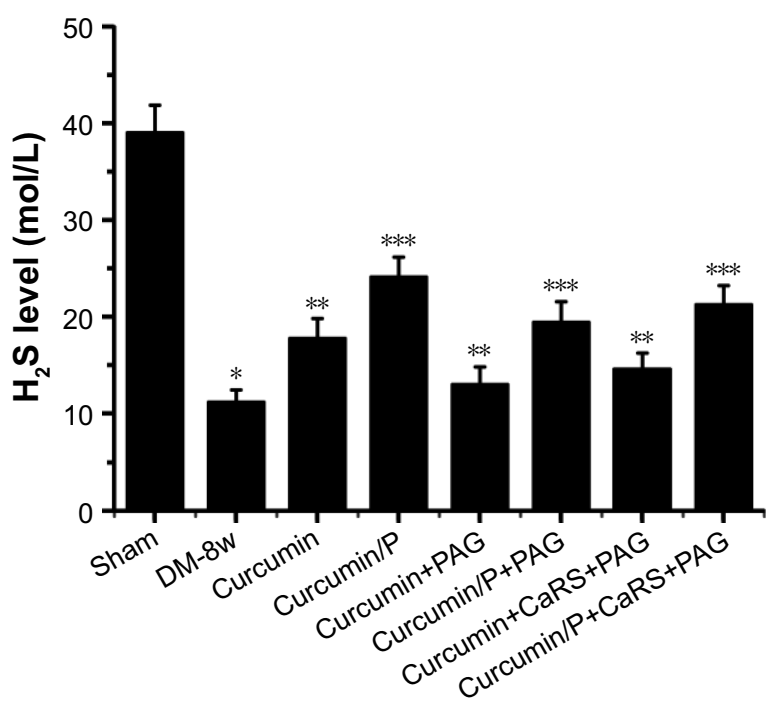

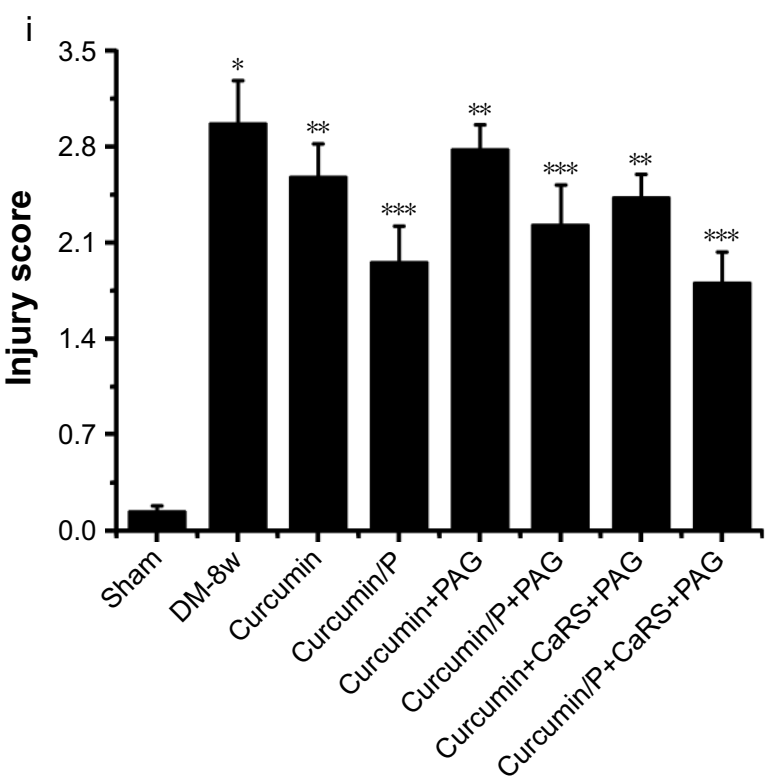

C

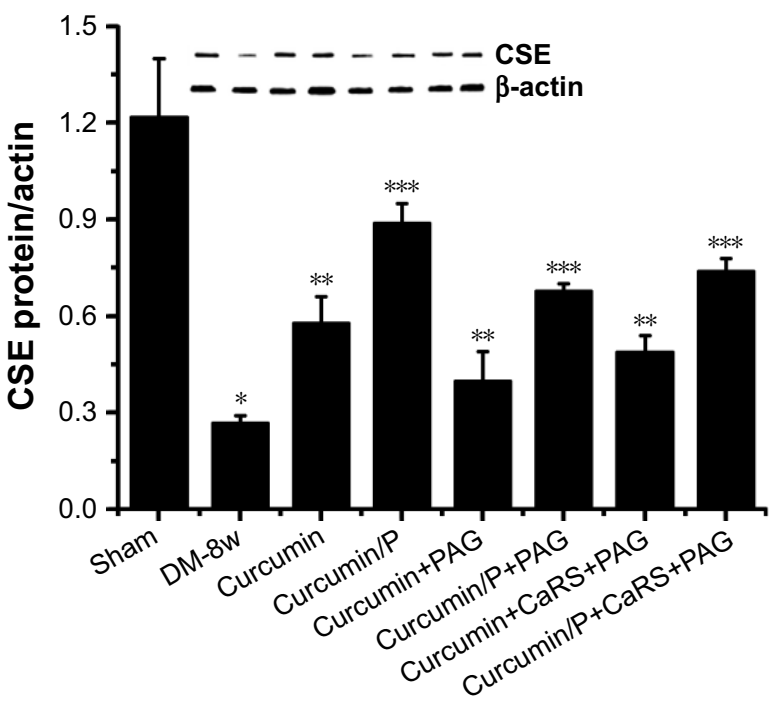

Figure 8 (A) Histopathologic assessment of myocardial damage; (B) $\mathrm{H}_{2} \mathrm{~S}$ level in Sham, DM-8w, Curcumin, Curcumin/P, Curcumin+PAG, Curcumin/P+PAG, Curcumin+ CaRS+PAG, and Curcumin/P+CaRS+PAG groups; (C) CSE expression in Sham, DM-8w, Curcumin, Curcumin/P, Curcumin+PAG, Curcumin/P+PAG, Curcumin+CaRS+ PAG, and Curcumin/P+CaRS+PAG groups.

Notes: (A) Light microscope images $(\times 100)$ in Sham group (a), DM-8w group (b), Curcumin group (c), Curcumin/P group (d), Curcumin+PAG group (e), Curcumin/P+PAG group (f), Curcumin+CaRS+PAG group (g), and Curcumin/P+CaRS+PAG group (h). The quantitative analysis of histopathologic assessment is showed in "i”". The histopathologic damage in DM-8w group is higher than that in Sham group $(p<0.01)$, and the histopathologic damage in Curcumin group, Curcumin $+P A G$ group, and Curcumin + CaRS+PAG group is lower than that in Sham group $(p<0.01)$; the histopathologic damage in Curcumin/P group, Curcumin/P+PAG group, and Curcumin/P+CaRS+PAG group is significantly lower than that in Sham group $(p<0.01)$. (B) The blood of Sham, DM-8w, Curcumin, Curcumin/P, Curcumin+PAG, Curcumin/P+PAG, Curcumin+CaRS+PAG, and Curcumin/ $\mathrm{P}+\mathrm{CaRS}+\mathrm{PAG}$ groups were collected and the levels of $\mathrm{H}_{2} \mathrm{~S}$ were measured. Results are expressed as mean $\pm \mathrm{SD}$. (C) The cardiac tissues of Sham, DM-8w, Curcumin, Curcumin/P, Curcumin+PAG, Curcumin/P+PAG, Curcumin+CaRS+PAG, and Curcumin/P+CaRS+PAG groups and the expression of CSE were measured. Results are expressed as mean \pm SD. A significant decrease from Sham group is denoted by $* p<0.0$ l, a significant increase from DM- $8 \mathrm{w}$ group is denoted by $* * p<0.0 \mathrm{I}$, and a significant increase from $D M-8 w$ group is denoted by $* * * p<0.01$.

Abbreviations: CaSR, calcium-sensing receptor; DM, diabetes mellitus; CSE, cystathionine- $\gamma$-lyase; CaRS, calcium-sensing receptor stimulator; PAG, DL-propargylglycine; CaM, calmodulin; P, poly(gamma-benzyl L-glutamate)-poly(ethylene glycol)-poly(gamma-benzyl L-glutamate); SD, standard deviation.

activity and regulate $\mathrm{CSE} / \mathrm{H}_{2} \mathrm{~S}$ via $\mathrm{CaM} / \mathrm{Ca}^{2+}$ pathway in smooth muscle cells in DM. ${ }^{50}$ Some studies had affirmed that $\mathrm{H}_{2} \mathrm{~S}$ production was physiologically modulated through calcium-calmodulin pathways. ${ }^{12} \mathrm{CaSR}$ activation augmented the expression of p-CaMK II and CSE, while the CaM antagonist KN93 restrained the expression in smooth muscle cells in DM. ${ }^{50}$ The results showed that CaSR regulated the expression of CSE via calcium-calmodulin pathway of VSMCs. ${ }^{50}$ In this study, we found that CaSR activation could increase CSE expression and $\mathrm{H}_{2} \mathrm{~S}$ level through upregulating 
CaM expression and $\mathrm{Ca}^{2+}$ level in DCM, while CaSR inhibition displayed opposite effect in DCM. In addition, curcumin as a yellow phenolic compound had a wide range of pharmacological effects, such as antioxidant, antitumor, anti-inflammatory, and hypolipidemic effects. ${ }^{23-26}$ Previous studies had corroborated that curcumin revealed therapeutic effects on diabetes, diabetic nephropathy, diabetic eye disease, insulin resistance and metabolism-related diseases, and diabetes-induced endothelial dysfunction. ${ }^{27-31}$ However, many studies found that curcumin alleviates DCM. ${ }^{2,32,33}$ In our study, both curcumin and curcumin/P reduced DCM through cross regulation effect of CaSR and endogenous $\mathrm{CSE} / \mathrm{H}_{2} \mathrm{~S}$, while curcumin/P significantly decreased DCM.

\section{Histopathologic assessment, $\mathrm{H}_{2} \mathrm{~S}$ level, and CSE expression (effect of CaRS and PAG)}

Light microscopy images of myocardium sections in Sham, DM-8w, Curcumin, Curcumin/P, Curcumin+PAG, Curcumin/P+PAG, Curcumin+CaRS+PAG, and Curcumin/ $\mathrm{P}+\mathrm{CaRS}+\mathrm{PAG}$ groups are shown in Figure 8A. The disordered arrangement of myocardial cells, inflammatory reactions, T-cell and activated macrophage infiltration, edema, myofibril disarray, cell death, fibrosis, myocardial cell membrane rupture and fuzzy edges, mitochondrial swelling, vacuolar degeneration, and derangement were observed in histological specimens from the DM-8w group (Figure 8A-a) but were absent in the Sham group (Figure 8A-b). The histopathologic damage in Curcumin group, Curcumin+PAG group, and Curcumin+CaRS+PAG group was lower than in DM-8w group (Figure 8A-c, e, g); the histopathologic damage in Curcumin/P group, Curcumin/P+PAG group, and Curcumin/P+CaRS+PAG group was significantly lower than in DM-8w group (Figure 8A-d, f, h). The quantitative analysis of histopathologic assessment is shown in Figure 8A-i.

$\mathrm{H}_{2} \mathrm{~S}$ level in Sham, DM-8w, Curcumin, Curcumin/P, Curcumin+PAG, Curcumin/P+PAG, Curcumin+CaRS+PAG, and Curcumin/P+CaRS+PAG groups are shown in Figure $8 \mathrm{~B}$. The $\mathrm{H}_{2} \mathrm{~S}$ level was significantly lower in DM-8w group than that in Sham group $\left(p<0.01 ; \mathrm{H}_{2} \mathrm{~S}\right.$ level: Sham group $39.1 \pm 2.79 \mathrm{~mol} / \mathrm{L}, \mathrm{DM}-8 \mathrm{w}$ group $11.3 \pm 1.18 \mathrm{~mol} / \mathrm{L}$ ). The $\mathrm{H}_{2} \mathrm{~S}$ level was higher in Curcumin group, Curcumin $+\mathrm{PAG}$ group, and Curcumin+CaRS+PAG group than that in DM-8w group $\left(p<0.01 ; \mathrm{H}_{2} \mathrm{~S}\right.$ level: Curcumin group $17.9 \pm 1.94 \mathrm{~mol} / \mathrm{L}$, Curcumin+PAG group $13.1 \pm 1.78 \mathrm{~mol} / \mathrm{L}$, Curcumin+CaRS+PAG group $14.7 \pm 1.59 \mathrm{~mol} / \mathrm{L}$ ). The $\mathrm{H}_{2} \mathrm{~S}$ level was significantly higher in Curcumin/P group, Curcumin/ $\mathrm{P}+\mathrm{PAG}$ group, and Curcumin/P+CaRS $+\mathrm{PAG}$ group than that in DM-8w group $\left(p<0.01 ; \mathrm{H}_{2} \mathrm{~S}\right.$ level: Curcumin/P group
24.2 $\pm 2.01 \mathrm{~mol} / \mathrm{L}$, Curcumin/P+PAG group $19.5 \pm 2.11 \mathrm{~mol} / \mathrm{L}$, Curcumin/P+CaRS+PAG group 21.4 $\pm 1.87 \mathrm{~mol} / \mathrm{L}$ ).

CSE expression in Sham, DM-8w, Curcumin, Curcumin/P, Curcumin+PAG, Curcumin/P+PAG, Curcumin+CaRS+PAG, and Curcumin/P+CaRS+PAG groups are shown in Figure $8 \mathrm{C}$. The CSE expression was significantly lower in DM-8w group than that in Sham group $(p<0.01)$. The CSE expression was higher in Curcumin group, Curcumin $+\mathrm{PAG}$ group, and Curcumin $+\mathrm{CaRS}+\mathrm{PAG}$ group than that in DM-8w group $(p<0.01)$. The CSE expression was significantly higher in Curcumin/P group, Curcumin/P+PAG group, and Curcumin/ $\mathrm{P}+\mathrm{CaRS}+\mathrm{PAG}$ group than in DM-8w group $(p<0.01)$.

Literature had showed that CaSR-mediated $\mathrm{H}_{2} \mathrm{~S}$ production in VSMCs through $\mathrm{Ca}^{2+}$ signaling could modulate the proliferation of VSMCs, ${ }^{50}$ and we found that $\mathrm{CaSR}$ could regulate $\mathrm{CSE} / \mathrm{H}_{2} \mathrm{~S}$ pathway to modulate DCM in this study. Both curcumin and curcumin/P alleviated DCM through CaSR-mediated endogenous $\mathrm{CSE} / \mathrm{H}_{2} \mathrm{~S}$ pathway, while curcumin/P remarkably alleviated DCM.

\section{Cell apoptosis}

Cardiac cell apoptosis in Sham, DM-8w, Curcumin, Curcumin/P, Curcumin+CaRS, Curcumin/P+CaRS, Curcumin+CaRI, and Curcumin/P+CaRI groups are shown in Figure 9A. The cardiac cell apoptosis was significantly higher in DM-8w group than that in Sham group (Figure 9A-a, b). The cardiac cell apoptosis was lower in Curcumin group, Curcumin+CaRS group, and Curcumin+CaRI group than that in DM-8w group (Figure 9A-c, e, g). The cardiac cell apoptosis was significantly lower in Curcumin/P group, Curcumin/P+CaRS group, and Curcumin/P+CaRI group than that in $\mathrm{DM}-8 \mathrm{w}$ group (Figure 9A-d, f, h).

Cardiac cell apoptosis in Sham, DM-8w, Curcumin, Curcumin/P, Curcumin+PAG, Curcumin/P+PAG, Curcumin $+\mathrm{CaRS}+\mathrm{PAG}$, and Curcumin $/ \mathrm{P}+\mathrm{CaRS}+\mathrm{PAG}$ groups are shown in Figure 9B. The cardiac cell apoptosis was significantly higher in DM-8w group than that in Sham group (Figure 9B-a, b). The cardiac cell apoptosis was lower in Curcumin group, Curcumin+PAG group, and Curcumin+CaRS+PAG group than in DM-8w group (Figure 9B-c, e, g). The cardiac cell apoptosis was significantly lower in Curcumin/P group, Curcumin/P+PAG group, and Curcumin $/ \mathrm{P}+\mathrm{CaRS}+\mathrm{PAG}$ group than in $\mathrm{DM}-8 \mathrm{w}$ group (Figure 9B-d, f, h).

Growing evidence supported that $\mathrm{CaSR}$ could regulate $\mathrm{CSE} / \mathrm{H}_{2} \mathrm{~S}$ to modulate apoptosis via $\mathrm{CaM} / \mathrm{Ca}^{2+}$ pathway in smooth muscle cells in DM. ${ }^{50}$ In our study, we found that CaSR activation promoted CSE expression and $\mathrm{H}_{2} \mathrm{~S}$ level to inhibit apoptosis in DCM, and both CaSR and CSE inhibitors 
A
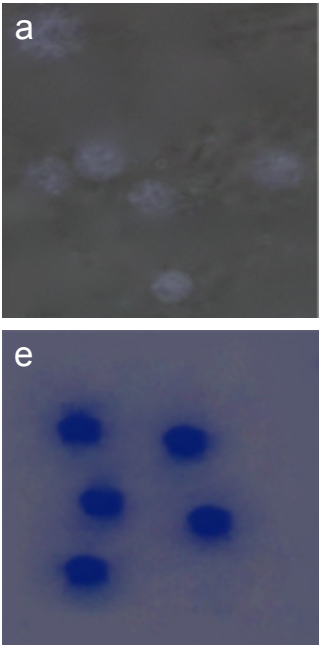

B
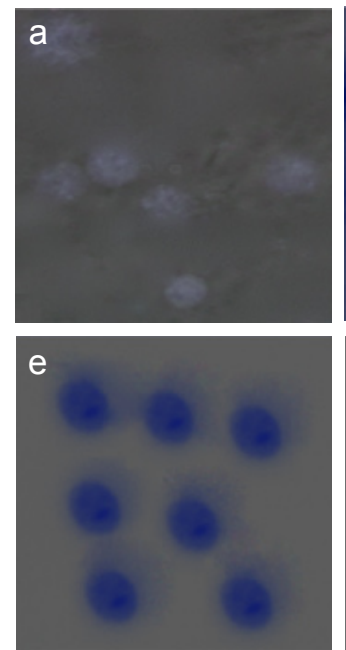
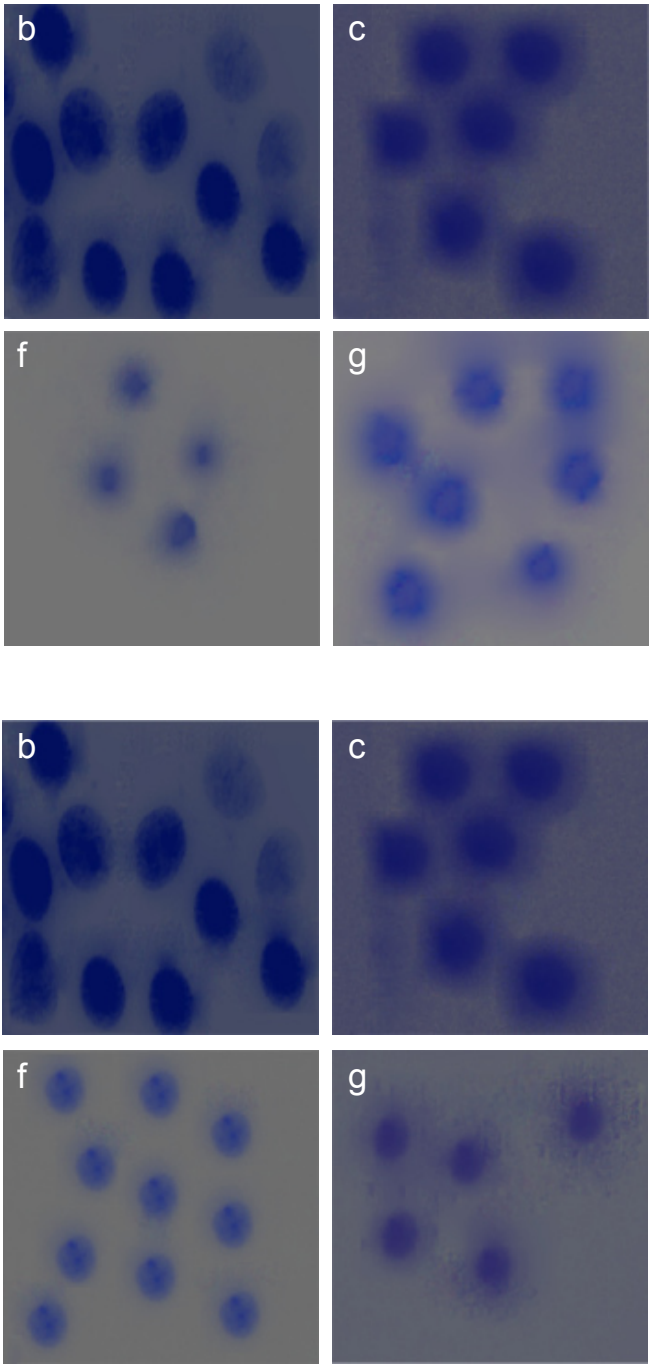
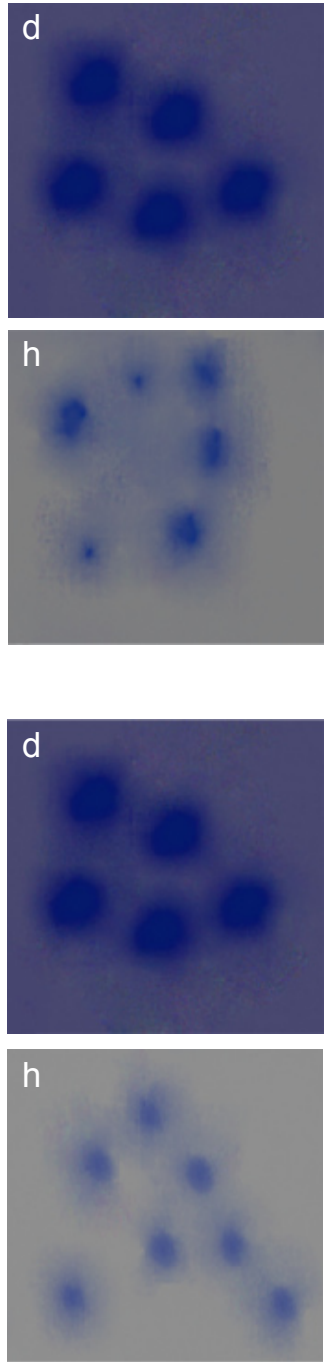

Figure 9 (A) Apoptosis assessment of cardiac cells in Sham, DM-8w, Curcumin, Curcumin/P, Curcumin+CaRS, Curcumin/P+CaRS, Curcumin+CaRI, and Curcumin/P+CaRI groups. (B) Apoptosis assessment of cardiac cell in Sham, DM-8w, Curcumin, Curcumin/P, Curcumin+PAG, Curcumin/P+PAG, Curcumin+CaRS+PAG, and Curcumin/ P+CaRS+PAG groups.

Notes: (A) Apoptosis in Sham group (a), DM-8w group (b), Curcumin group (c), Curcumin/P group (d), Curcumin+CaRS group (e), Curcumin/P+CaRS group (f), Curcumin+CaRI group $(\mathrm{g})$, and Curcumin/P+CaRI group $(\mathrm{h})$. The apoptosis in DM-8w group is higher than that in Sham group, and the apoptosis in Curcumin group, Curcumin+CaRS group, and Curcumin+CaRI group is lower than that in DM-8w group; the apoptosis in Curcumin/P group, Curcumin/P+CaRS group, and Curcumin/P+CaRI group is significantly lower than that in DM-8w group. (B) Apoptosis in Sham group (a), DM-8w group (b), Curcumin group (c), Curcumin/P group (d), Curcumin+PAG group (e), Curcumin/P+PAG group (f), Curcumin+CaRS+PAG group (g), and Curcumin/P+CaRS+PAG group (h). The apoptosis in DM-8w group is higher than that in Sham group, and the apoptosis in Curcumin group, Curcumin+PAG group, and Curcumin+CaRS+PAG group is lower than that in DM-8w group; the apoptosis in Curcumin/P group, Curcumin/P+PAG group, and Curcumin/P+CaRS+PAG group is significantly lower than that in DM- 8 w group. Magnification is $\times 100$.

Abbreviations: CaSR, calcium sensing receptor; DM, diabetes mellitus; CaRS, calcium-sensing receptor stimulator; CaRI, calcium-sensing receptor inhibitor; $\mathrm{P}$, poly(gammabenzyl L-glutamate)-poly(ethylene glycol)-poly(gamma-benzyl L-glutamate); PAG, DL-propargylglycine.

could increase apoptosis in DCM. These results showed that the cross regulation effect of CaSR and endogenous CSE/ $\mathrm{H}_{2} \mathrm{~S}$ modulated DCM. Previous documents had proved that curcumin could inhibit apoptosis, ${ }^{57,58}$ and our research findings also found that curcumin and curcumin/P both could restrained apoptosis to alleviate DCM by the cross regulation effect of CaSR and endogenous $\mathrm{CSE} / \mathrm{H}_{2} \mathrm{~S}$, while curcumin/P remarkably restrained apoptosis to alleviate DCM.

To sum up, this study showed that synthesized P could significantly improve the bioactivity, water solubility, and short half-life of curcumin. In addition, it demonstrated that curcumin and curcumin/P preconditioning were both capable of reducing DCM, and curcumin/P preconditioning significantly reduced DCM through the cross regulation effect of $\mathrm{CaSR}$ and endogenous $\mathrm{CSE} / \mathrm{H}_{2} \mathrm{~S}$.

\section{Conclusion}

The use of $\mathrm{P}$ as a curcumin delivery carrier not only improved half-time and bioactivity but also enhanced water solubility of curcumin. The design of $\mathrm{P}$ with low cytotoxicity and 
high efficiency was important for developing a successful curcumin delivery system. In our study, $\mathrm{P}$ as a curcumin nanocarrier with biodegradability and high loading capacity enhanced the pharmacological action of curcumin. Both curcumin and curcumin/P could decrease DCM through the cross regulation effect of $\mathrm{CaSR}$ and endogenous $\mathrm{CSE} / \mathrm{H}_{2} \mathrm{~S}$.

\section{Acknowledgment}

This study was financially supported through the Science and Technology Planning Project of Jiaxing, Zhejiang Province (2017AY33076).

\section{Disclosure}

The authors report no conflicts of interest in this study.

\section{References}

1. King H, Aubert RE, Herman WH. Global burden of diabetes, 1995-2025 prevalence, numerical estimates, and projections. Diabetes Care. 1998; 21:1414-1431.

2. Yu W, Wu J, Cai F, et al. Curcumin alleviates diabetic cardiomyopathy in experimental diabetic rats. PLoS One. 2012;7:e52013.

3. Mano Y, Anzai T, Kaneko H, et al. Overexpression of human C-reactive protein exacerbates left ventricular remodeling in diabetic cardiomyopathy. Circ J. 2011;75:1717-1727.

4. Wang J, Wang H, Hao P, et al. Inhibition of aldehyde dehydrogenase 2 by oxidative stress is associated with cardiac dysfunction in diabetic rats. Mol Med. 2011;17:172-179.

5. Zhou H, Li YJ, Wang M, et al. Involvement of RhoA/ROCK in myocardial fibrosis in a rat model of type 2 diabetes. Acta Pharmacol Sin 2011;32:999-1008.

6. Thandavarayan RA, Watanabe K, Ma M, et al. Dominant-negative p38alpha mitogen-activated protein kinase prevents cardiac apoptosis and remodeling after streptozotocin-induced diabetes mellitus. Am J Physiol Heart Circ Physiol. 2009;297:H911-H919.

7. Duncan JG. Mitochondrial dysfunction in diabetic cardiomyopathy. Biochim Biophys Acta. 2011;1813:1351-1359.

8. Kimura H. Hydrogen sulfide: its production, release and functions. Amino Acids. 2011;41:113-121.

9. Papapetropoulos A, Pyriochou A, Altaany Z, et al. Hydrogen sulfide is an endogenous stimulator of angiogenesis. Proc Natl Acad Sci U S A 2009;106:21972-21977.

10. Wang R. Two's company, three's a crowd: can H2S be the third endogenous gaseous transmitter? FASEB J. 2002;16:1792-1798.

11. Tang G, Wu L, Wang R. Interaction of hydrogen sulfide with ion channels. Clin Exp Pharmacol Physiol. 2010;37:753-763.

12. Yang G, Wu L, Jiang B, et al. H2S as a physiologic vasorelaxant: hypertension in mice with deletion of cystathionine gamma-lyase. Science. 2008;322:587-590.

13. Yang G, Wu L, Bryan S, et al. Cystathionine gamma-lyase deficiency and overproliferation of smooth muscle cells. Cardiovasc Res. 2010;86: 487-495.

14. Yang G, Wu L, Wang R. $\mathrm{H}_{2} \mathrm{~S}$, endoplasmic reticulum stress, and apoptosis of insulin-secreting beta cells. J Biol Chem. 2007;282:16567-16576.

15. Yang W, Yang G, Jia X, et al. Activation of KATP channels by H2S in rat insulin-secreting cells and the underlying mechanisms. J Physiol (Lond). 2005;569:519-531.

16. Yang R, Jia Q, Liu XF, et al. Effects of hydrogen sulfide on oxidative stress and endoplasmic reticulum stress in rats with diabetic cardiomyopathy. Chin J Appl Physiol. 2016;32:8-12.

17. Chang W, Shoback D. Extracellular $\mathrm{Ca}^{2+}$-sensing receptors - an overview. Cell Calcium. 2004;35:183-196.

18. Jia Z, Sun J, Li HZ, et al. Effects of calcium sensing receptor on diabetic cardiomyopathy in rats. Chin J Appl Physiol. 2015;31:35-37.
19. Zhang WH, Fu SB, Lu FH, et al. Involvement of calcium-sensing receptor in ischemia/reperfusion-induced apoptosis in rat cardiomyocytes. Biochem Biophys Res Commun. 2006;347:872-881.

20. Zhang WH, Lu FH, Zhao YJ, et al. Post-conditioning protects rat cardiomyocytes via PKCe-mediated calcium-sensing receptors. Biochem Biophys Res Commun. 2007;361:659-664.

21. Zhao W, Wang R. $\mathrm{H}_{2} \mathrm{~S}$-induced vasorelaxant and the underlying cellular and molecular mechanisms. Am J Physiol Heart Circ Physiol. 2002; 283:H474-H480.

22. Yang G, Sun X, Wang R. Hydrogen sulfide-induced apoptosis of human aorta smooth muscle cells via the activation of mitogen-activated protein kinases and caspase-3. Faseb J. 2004;18:1782-1784.

23. Ramsewak RS, Dewitt DL, Nair MG. Cytotoxicity, antioxidant and anti-inflammatory activities of curcumins I-III from Curcuma longa. Phytomedicine. 2000;7:303-308.

24. Tian B, Wang Z, Zhao Y, et al. Effects of curcumin on bladder cancer cells and development of urothelial tumors in a rat bladder carcinogenesis model. Cancer Lett. 2008;264:299-308.

25. Gukovsky I, Reyes CN, Vaquero EC, et al. Curcumin ameliorates ethanol and nonethanol experimental pancreatitis. Am J Physiol Gastrointest Liver Physiol. 2003;284:G85-G95.

26. Asai A, Miyazawa T. Dietary curcuminoids prevent high-fat dietinduced lipid accumulation in rat liver and epididymal adipose tissue. J Nutr. 2001;131:2932-2935.

27. Soetikno V, Sari FR, Veeraveedu PT, et al. Curcumin ameliorates macrophage infiltration by inhibiting NF-kappaB activation and proinflammatory cytokines in streptozotocin induced-diabetic nephropathy. Nutr Metab (Lond). 2011;8:35.

28. Sharma S, Chopra K, Kulkarni SK. Effect of insulin and its combination with resveratrol or curcumin in attenuation of diabetic neuropathic pain: participation of nitric oxide and TNF-alpha. Phytother Res. 2007; $21: 278-283$

29. Suryanarayana P, Saraswat M, Mrudula T, et al. Curcumin and turmeric delay streptozotocin-induced diabetic cataract in rats. Invest Ophthalmol Vis Sci. 2005;46:2092-2099.

30. Shehzad A, Ha T, Subhan F, et al. New mechanisms and the antiinflammatory role of curcumin in obesity and obesity-related metabolic diseases. Eur J Nutr. 2011;50:151-161.

31. Rungseesantivanon $\mathrm{S}$, Thenchaisri N, Ruangvejvorachai $\mathrm{P}$, et al. Curcumin supplementation could improve diabetes-induced endothelial dysfunction associated with decreased vascular superoxide production and PKC inhibition. BMC Complement Altern Med. 2010;10:57.

32. Guo S, Meng XW, Yang XS, et al. Curcumin administration suppresses collagen synthesis in the hearts of rats with experimental diabetes. Acta Pharmacol Sin. Epub 2017 Sep 14.

33. Chen H, Yang X, Lu K, et al. Inhibition of high glucose-induced inflammation and fibrosis by a novel curcumin derivative prevents renal and heart injury in diabetic mice. Toxicol Lett. 2017;278:48-58.

34. Wahlsrtom B, Blennow GA. A study on the fate of curcumin in rats. Acta Phamacol Toxicol. 1978;43:86-92.

35. Ireson CR, Jones DJ, Orr S, et al. Metabolism of the cancer chemopreventive agent curcumin in human and rat intestine. Cancer Epidemiol Biomarkers Prev. 2002;11:105-111.

36. Ireson CR, Orr S, Jones DJ, et al. Characterization of metabolites of the chemopreventive agent curcumin in human and rat hepatocytes and in the rat in vivo, and evaluation of the ability to inhibit phorbol ester-induced prostaglandin E2 production. Cancer Res. 2001;61:1058-1064.

37. Wang QM, Teng W, Zhang JX, et al. Circular dichroism spectrum analysis of poly(benzyl L-glutamate)/poly(ethylene glycol)/ poly(benzyl L-glutamate) block copolymer. Chin J Anal Lab. 2006;25: $112-115$.

38. Wang QM, Teng W, Pan SR, et al. The biodegradation of block copolymer membranes of poly (benzyl L-glutamate)/poly(ethylene glycol)/ poly (benzyl L-glutanate). Beijing Biomed Eng. 2004;23:40-42.

39. Tong F, Zhang H. Poly (ethylene glycol)-block-brush poly (L-lysine) copolymer as an efficient nanocarrier for human hepatocyte growth factor with enhanced bioavailability and anti-ischemia reperfusion injury efficacy. Kidney Blood Press Res. 2017;42:495-508. 
40. Tong F. Preparation of exenatide-loaded linear poly(ethylene glycol)brush poly(l-lysine) block copolymer: potential implications on diabetic nephropathy. Int J Nanomedicine. 2017;12:4663-4678.

41. Tong F, Tang X, Luo L, et al. Sustained delivery of insulin-loaded block copolymers: potential implications on renal ischemia/reperfusion injury in diabetes mellitus. Biomed Pharmacother. 2017;91:534-545.

42. Tong F, Dong B, Chai R, et al. Simvastatin nanoparticles attenuated intestinal ischemia/reperfusion injury by downregulating BMP4/COX-2 pathway in rats. Int J Nanomedicine. 2017;12:2477-2488.

43. Tong F, Tang X, Li X, et al. The effect of insulin-loaded linear poly(ethylene glycol)-brush-like poly(l-lysine) block copolymer on renal ischemia/reperfusion-induced lung injury through downregulating hypoxia-inducible factor. Int J Nanomedicine. 2016;11:1717-1730.

44. Ding Y, Vaziri ND, Coulson R, et al. Effects of stimulated hyperglycemia, insulin, and glucagon on endothelial nitric oxide synthase expression. Am J Physiol Endocrinol Metab. 2000;279:E11-E17.

45. Ma S, Feng J, Zhang R, et al. SIRT1 activation by resveratrol alleviates cardiac dysfunction via mitochondrial regulation in diabetic cardiomyopathy mice. Oxid Med Cell Longev. 2017;2017:4602715.

46. Uchiyama T, Tatsumi N, Kamejima S, et al. Hypermethylation of the CaSR and VDR genes in the parathyroid glands in chronic kidney disease rats with high-phosphate diet. Hum Cell. 2016;29:155-161.

47. Zhang HX, Du JM, Ding ZN, et al. Hydrogen sulfide prevents diaphragm weakness in cecal ligation puncture-induced sepsis by preservation of mitochondrial function. Am J Transl Res. 2017;9:3270-3281.

48. Weekers L, de Tullio P, Bovy C, et al. Activation of the calcium-sensing receptor before renal ischemia/reperfusion exacerbates kidney injury. Am J Transl Res. 2015;7:128-138.

49. Hu J, Zhu L, Yang SJ, et al. Effects of hydrogen sulfide on the expression of inflammatory markers in pancreatic tissues in rats with type 2 diabetes. Acta Med U Sci et Technol Huazhong (Chin). 2014;43:296-299.
50. Zhong $\mathrm{X}$, Wang $\mathrm{Y}, \mathrm{Wu}$, et al. Calcium sensing receptor regulating smooth muscle cells proliferation through initiating cystathioninegamma-lyase/hydrogen sulfide pathway in diabetic rat. Cell Physiol Biochem. 2015;35:1582-1598.

51. Tian R, Gong ZH, Yang XY, et al. Study on interference effect of Sijunzi decoction on brain-gut CaM/CaMK II of spleen Qi deficiency syndrome rats. Zhongguo Zhong Yao Za Zhi. 2015;40:4075-4079.

52. Xue Z, Song Z, Wan Y, et al. Calcium-sensing receptor antagonist NPS2390 attenuates neuronal apoptosis though intrinsic pathway following traumatic brain injury in rats. Biochem Biophys Res Commun. 2017;486:589-594.

53. Xu QL, Jin XD, Zhang XD, et al. Effect and mechanism research of curcumin on NF- $\mathrm{KB}$ in myocardium of diabetic cardiomyopathy rats. Liaoning J Tradit Chin Med (Chin). 2013;40:2603-2605.

54. Chen L, Phillips MI, Miao HL, et al. Infrared fluorescent protein 1.4 genetic labeling tracks engrafted cardiac progenitor cells in mouse ischemic hearts. PLoS One. 2014;9:e107841.

55. Cooper GJ, Phillips AR, Choong SY, et al. Regeneration of the heart in diabetes by selective copper chelation. Diabetes. 2004;53: 2501-2508.

56. Wilkerson MK, Heppner TJ, Bonev AD, et al. Inositol trisphosphate receptor calcium release is required for cerebral artery smooth muscle cell proliferation. Am J Physiol Heart Circ Physiol. 2006;290:H240-H247.

57. Parmar MS, Syed I, Gray JP, et al. Curcumin, hesperidin, and rutin selectively interfere with apoptosis signaling and attenuate streptozotocininduced oxidative stress-mediated hyperglycemia. Curr Neurovasc Res. 2015;12:363-374

58. Bulku E, Stohs SJ, Cicero L, et al. Curcumin exposure modulates multiple pro-apoptotic and anti-apoptotic signaling pathways to antagonize acetaminophen-induced toxicity. Curr Neurovasc Res. 2012;9: $58-71$. 


\section{Supplementary materials}

H $\curvearrowright O \sim \mathrm{NH}_{2}$

$\mathrm{H}_{2} \mathrm{~N}-\mathrm{PEG}-\mathrm{NH}_{2}$

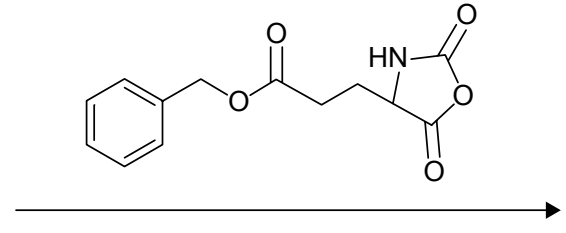

DMF

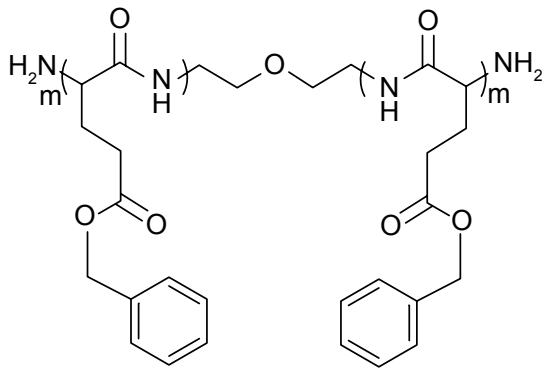

PBLG-PEG-PBLG

Figure SI The synthesis of PBLG-PEG-PBLG (P).

Abbreviations: $\mathrm{H}_{2} \mathrm{~N}-\mathrm{PEG}-\mathrm{NH}_{2}$, amine poly(ethylene glycol) amine; DMF, N, N-dimethylformamide; P, poly(gamma-benzyl L-glutamate)-poly(ethylene glycol)-poly(gammabenzyl L-glutamate)

A

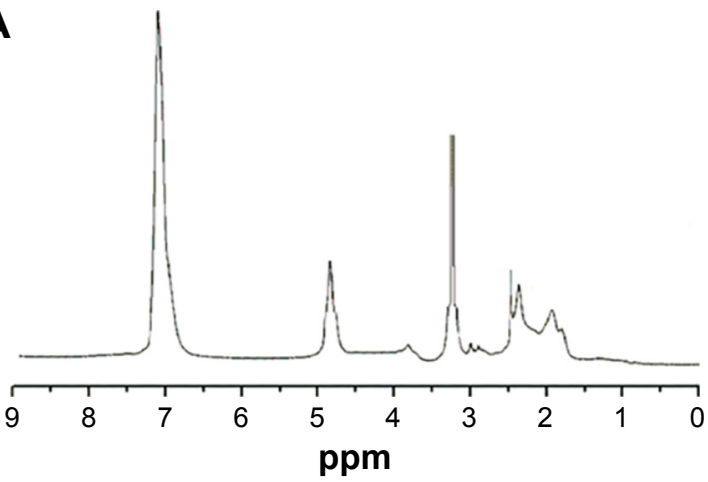

B

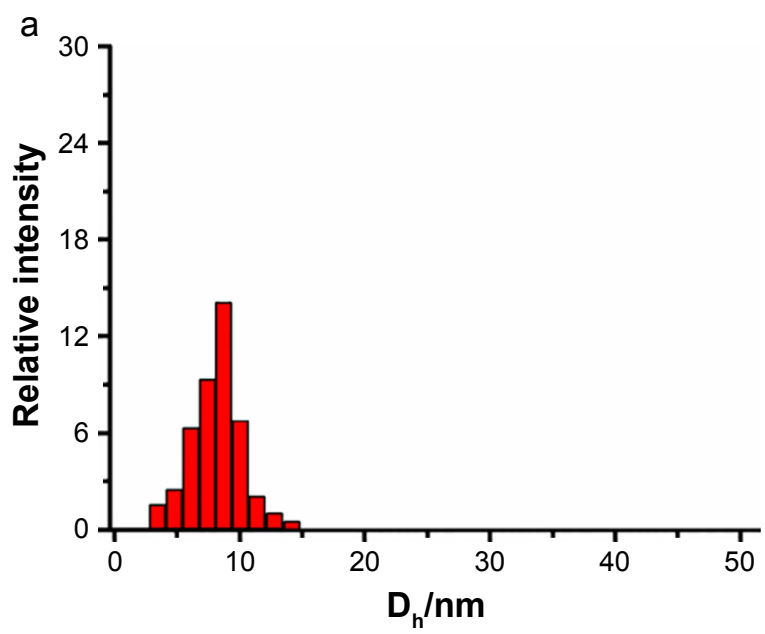

b

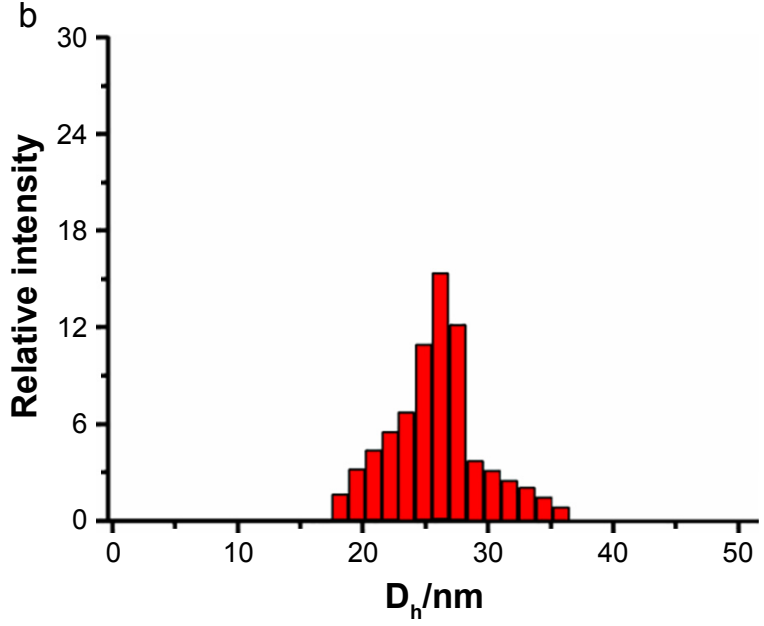

Figure S2 'H NMR spectra of $P(\mathbf{A})$, diameter of $P$ in $P B(B-a)$, and diameter of curcumin/P complexes in $P B(B-b)$.

Abbreviations: P, poly(gamma-benzyl L-glutamate)-poly(ethylene glycol)-poly(gamma-benzyl L-glutamate); 'H NMR, 'H-nuclear magnetic resonance; PB, phosphate buffer. 
Table SI Molecular weights, particle size, TEM, and curcumin-loading capacity of $\mathrm{P}$

\begin{tabular}{lllll}
\hline Sample & $\mathbf{M}_{\mathbf{n}}(\mathbf{k D a}) / \mathbf{H} \mathbf{H}$ NMR & Particle size $(\mathbf{n m})$ & TEM $(\mathbf{n m})$ & Loading capacity $(\%)$ \\
\hline $\mathrm{P}$ & 29.8 & 12 & 47 & NA \\
Curcumin/P & NA & 30 & 85 & 32.3 \\
\hline
\end{tabular}

Abbreviations: P, poly(gamma-benzyl L-glutamate)-poly(ethylene glycol)-poly(gamma-benzyl L-glutamate); 'H NMR, IH-nuclear magnetic resonance; TEM, transmission electron microscopy; $M_{\mathrm{n}}$, number-average molecular weight; NA, not applicable.

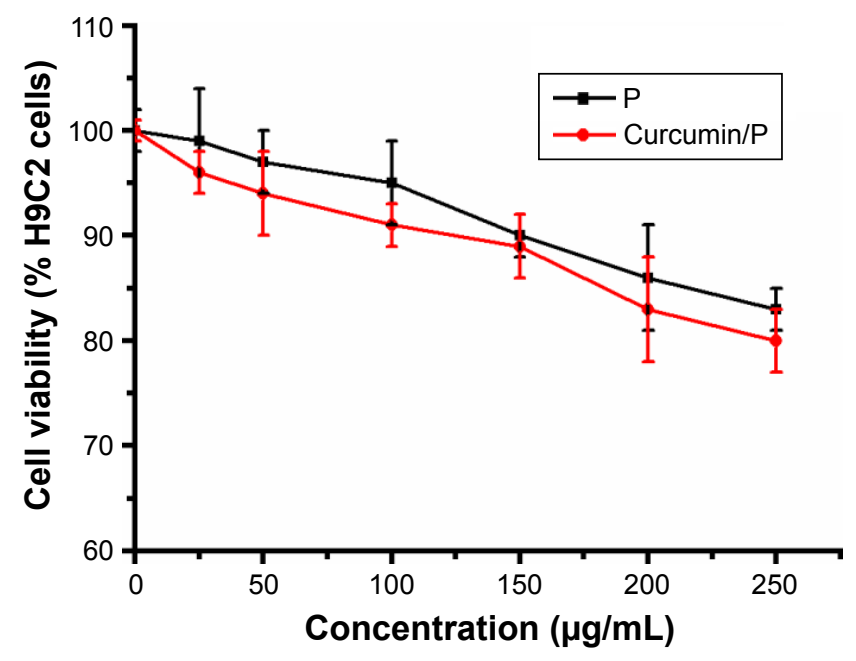

Figure S3 The cellular viability of $\mathrm{H} 9 \mathrm{C} 2$ cells cultured with different concentrations of $\mathrm{P}$ and curcumin/P. Abbreviation: P, poly(gamma-benzyl L-glutamate)-poly(ethylene glycol)-poly(gamma-benzyl L-glutamate).

\section{Publish your work in this journal}

The International Journal of Nanomedicine is an international, peerreviewed journal focusing on the application of nanotechnology in diagnostics, therapeutics, and drug delivery systems throughout the biomedical field. This journal is indexed on PubMed Central, MedLine, CAS, SciSearch ${ }^{\circledR}$, Current Contents ${ }^{\circledR} /$ Clinical Medicine,
Journal Citation Reports/Science Edition, EMBase, Scopus and the Elsevier Bibliographic databases. The manuscript management system is completely online and includes a very quick and fair peer-review system, which is all easy to use. Visit http://www.dovepress.com/ testimonials.php to read real quotes from published authors. 